Universidad de Lima

Facultad de Ingeniería y Arquitectura

Carrera de Ingeniería Industrial

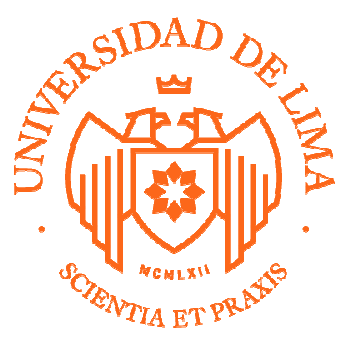

\title{
ESTUDIO DE MEJORA DE LA LÍNEA DE PRODUCCIÓN Y COMERCIALIZACIÓN DEL DELIVERY DE BEMBOS S.A.
}

Trabajo de suficiencia profesional para optar el Título Profesional de Ingeniero Industrial

Carlos Adolfo Noriega Niño de Guzmán

Código 19863083

Asesor

Fernando Kleeberg Hidalgo

Lima - Perú

Septiembre de 2019 


\section{IMPROVEMENT STUDY OF THE PRODUCTION AND COMMERCIALIZATION BEMBOS S.A.' DELIVERY LINE}




\section{TABLA DE CONTENIDO}

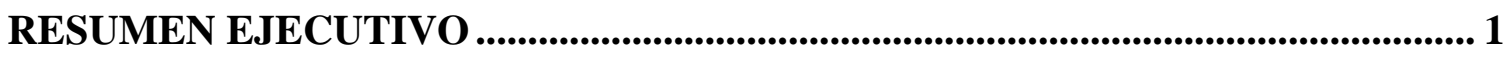

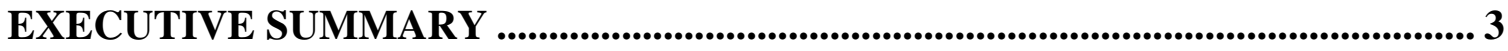

CAPÍTULO I: ANTECEDENTES DE LA EMPRESA ................................................. 5

1.1 Breve descripción de la empresa y reseña histórica. ............................................ 5

1.1.1 Visión, misión y objetivos organizacionales. ................................................... 9

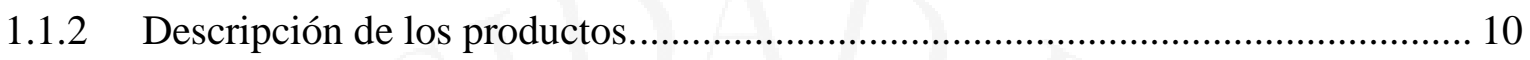

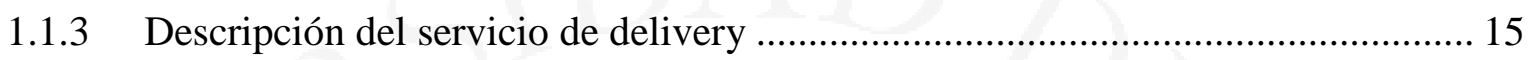

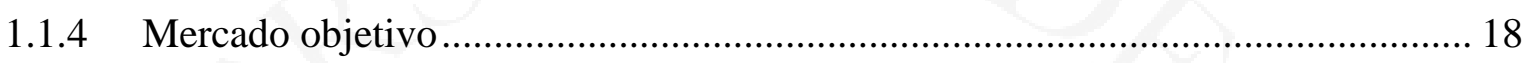

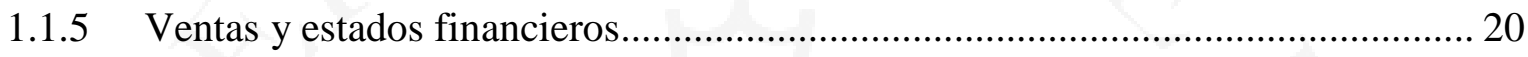

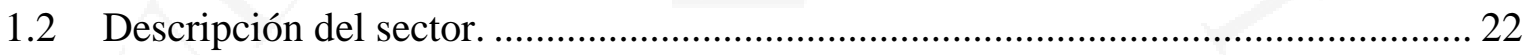

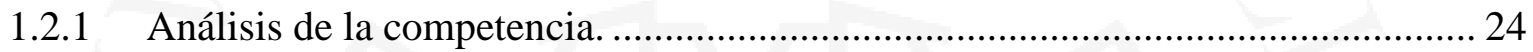

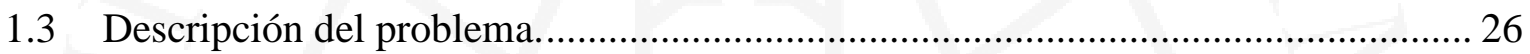

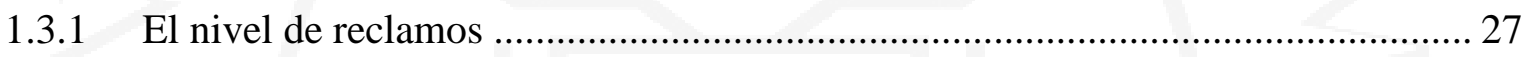

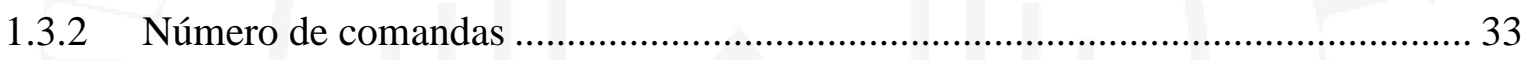

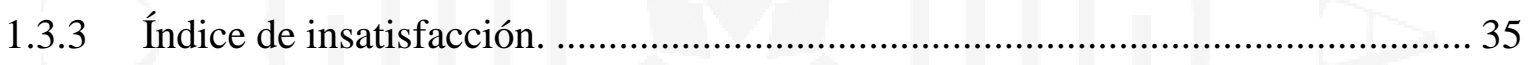

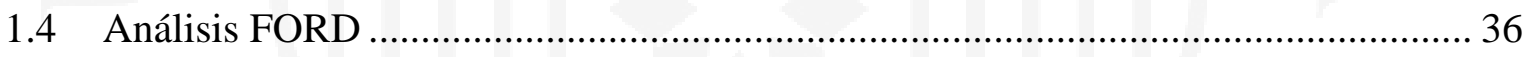

CAPÍTULO II: OBJETIVOS DE LA INVESTIGACIÓN ............................................... 38

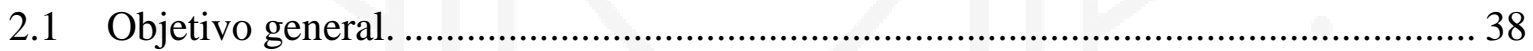

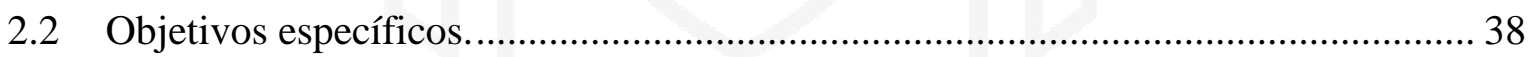

CAPÍTULO III: ALCANCE Y LIMITACIONES DE LA INVESTIGACIÓN .......... 39

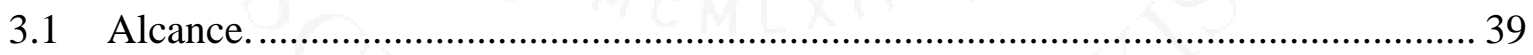

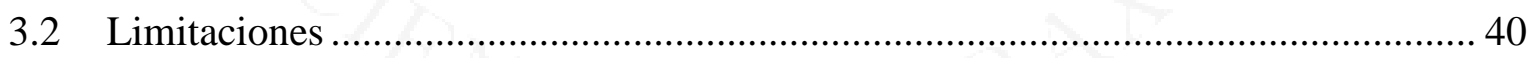

CAPÍTULO IV: JUSTIFICACIÓN DE LA INVESTIGACIÓN ................................... 41

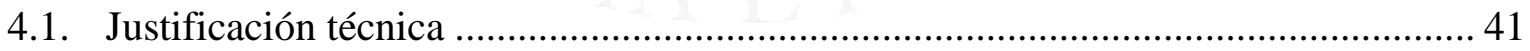

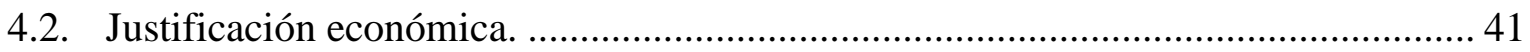

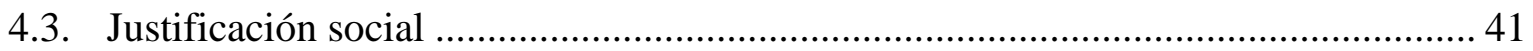

CAPÍTULO V: PROPUESTAS Y RESULTADOS........................................................... 42

5.1 Identificación de las causas raíces del problema.................................................... 42

5.2 Soluciones propuestas para los problemas encontrados......................................... 44

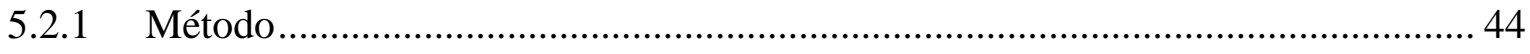

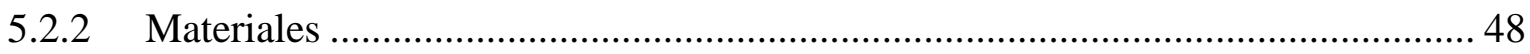




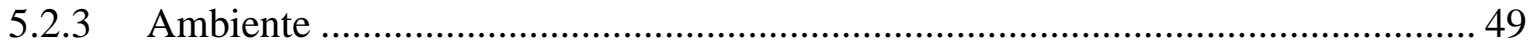

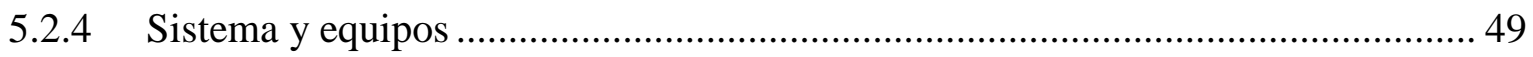

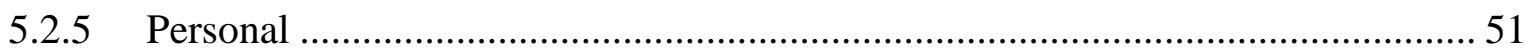

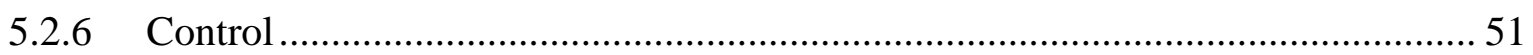

5.3 Implementación de las soluciones elegidas.......................................................... 52

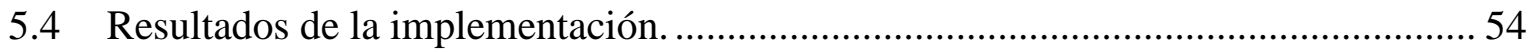

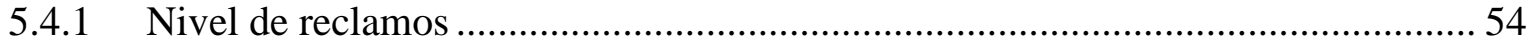

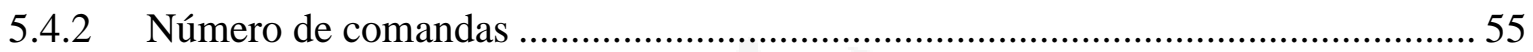

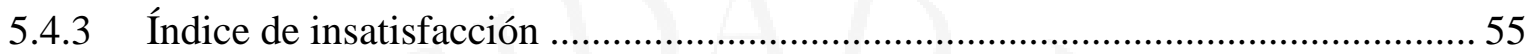

5.4.4 Tiempo total de atención después de las mejoras.............................................. 56

5.4.5 Ventas de la línea de delivery después de las soluciones.................................... 57

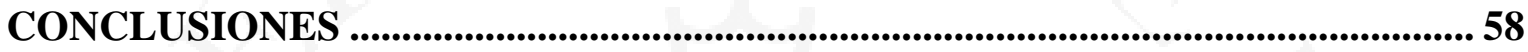

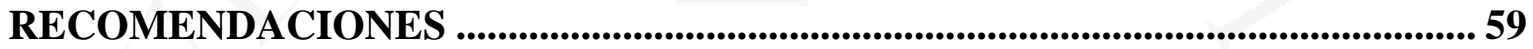

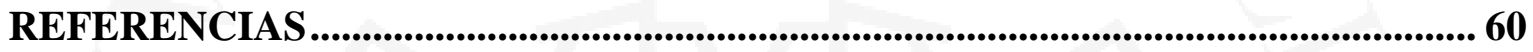

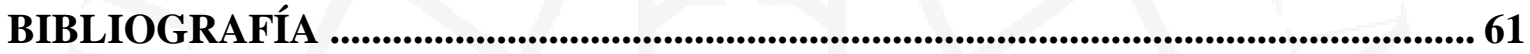

ANEXOS 


\section{ÍNDICE DE TABLAS}

Tabla 1.1 Listado de locales que ofrecían el servicio de delivery en Bembos, 1997 .... 7

Tabla 1.2 Tamaños de hamburguesas en Bembos, 1997 f............................................ 11

Tabla 1.3 Listado de productos generales ofrecidos por Bembos, 1997 ....................... 12

Tabla 1.4 Tamaños de la oferta de papas fritas en Bembos, 1997................................ 13

Tabla 1.5 Precios y costos promedio por producto, 1997 ............................................ 14

Tabla 1.6 Margen bruto unitario en soles del producto hamburguesa en Bembos,

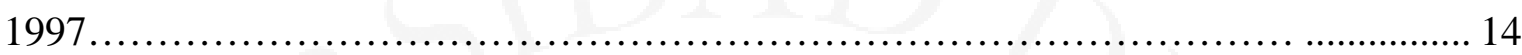

Tabla 1.7 Margen bruto unitario en soles del producto papas fritas en Bembos, 1997. 15

Tabla 1.8 Ticket promedio de venta soles en delivery por local, enero-abril, 1997..... 18

Tabla 1.9 Número de hogares por distrito y nivel socioeconómico (NSE), 1997 ......... 19

Tabla 1.10 Características de los niveles socioeconómicos: alto, medio alto y medio, 1997.

Tabla 1.11 Principales cifras financieras de Bembos, 1997-2001 ................................... 21

Tabla 1.12 Competencia directa e indirecta de Bembos, 1997 ..................................... 24

Tabla 1.13 Oferta delivery de la competencia principal, 1997 …................................. 25

Tabla 1.14 Clasificación de reclamos del buzón de sugerencias, 1997 ............................ 28

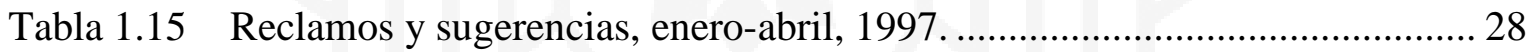

Tabla 1.16 División por tipo de reclamos en buzón de sugerencias, enero-abril, 1997 .. 29

Tabla 1.17 Reclamos de producto por línea de atención, enero-abril, 1997. ................... 30

Tabla 1.18 División de los reclamos por tipo de producto, enero-abril, 1997. ............... 32

Tabla 1.19 Reclamos de producto por tipo de problema, enero-abril, 1997. ................... 32

Tabla 1.20 Índice de insatisfacción de la línea de delivery de Bembos, enero-abril,

1997

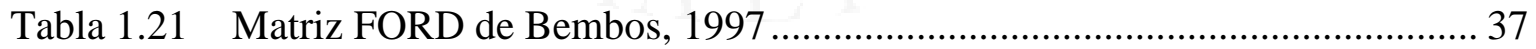

Tabla 3.1. Áreas y funciones en la línea de delivery de Bembos, 1997........................ 39

Tabla 5.1 Fórmula de cálculo del tiempo total de atención en delivery ........................ 45

Tabla 5.2 Resultados muestreo: tiempo total de atención delivery, abril 1997............. 46

Tabla 5.3 Soluciones para la causa: método, 1997................................................... 47

Tabla 5.4 Inversiones, costos y gastos en las soluciones de la causa: método, $1997 \ldots . .47$

Tabla 5.5 Soluciones para la causa: materiales, 1997 ................................................. 48

Tabla 5.6 Nuevo costo de empaque para la solución de la causa: material, 1997......... 48 
Tabla 5.7 Solución para la causa: ambiente, 1997...................................................... 49

Tabla 5.8 Solución para la causa: sistemas y equipos, 1997 ....................................... 50

Tabla 5.9 Inversión, costo y gastos en la solución de la causa: sistemas y equipos,

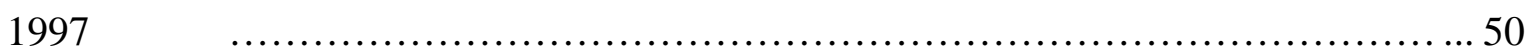

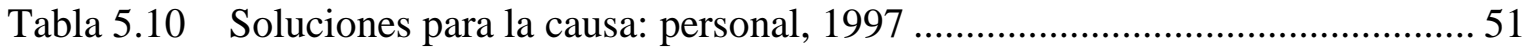

Tabla 5.11 Solución para la causa: control, 1997........................................................ 52

Tabla 5.12 Resultado muestreo: tiempo total de atención del delivery por local, mayojunio, 1997 


\section{ÍNDICE DE FIGURAS}

Figura 1.1 Ejemplo de diseño de un local de Bembos .............................................. 5

Figura 1.2 Ejemplo de decoracion de ambientes en los locales de Bembos ................... 6

Figura 1.3 Planta central de fabricación de productos de Bembos ................................ 8

Figura 1.4 Hamburguesa Clásica de Bembos ............................................................ 11

Figura 1.5 Ejemplo de un combo en la oferta de Bembos ........................................... 13

Figura 1.6 Flujo del proceso de atención del delivery en Bembos, 1997 ....................... 16

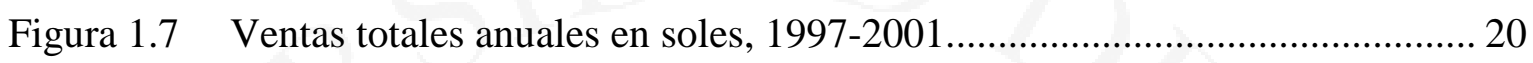

Figura 1.8 Ventas en soles de la línea delivery Bembos, enero-abril, 1997 ................... 22

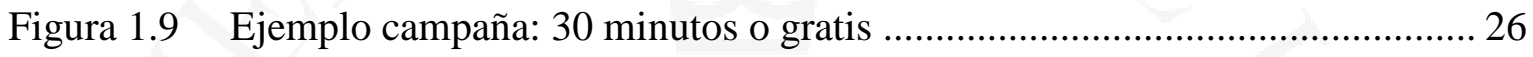

Figura 1.10 Grafica de Pareto: división por tipo de reclamos en buzón de sugerencias,

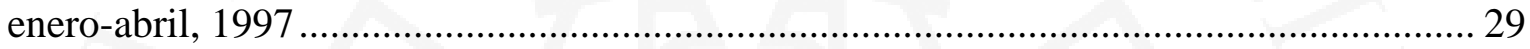

Figura 1.11 Curva de comportamiento mes del total de reclamos, enero-abril, 1997 ...... 30

Figura 1.12 Distribución de los reclamos por la línea de atención, enero-abril, 1997. .... 31

Figura 1.13 Curva de comportamiento mes de los reclamos del delivery, enero-

abril,1997

Figura 1.14 Curva de Pareto: división de los problemas de los reclamos del producto hamburguesa, enero-abril, 1997

Figura 1.15 Comandas por mes del total de la línea de delivery, enero-abril, 1997......... 34

Figura 1.16 Comportamiento mes del índice de insatisfacción, enero-abril, 1997........... 36

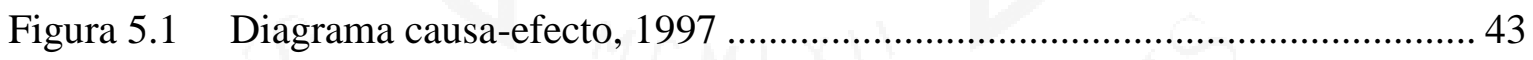

Figura 5.2 Cronograma de implementación de mejoras, 1997 .................................... 53

Figura 5.3 Número de reclamos del producto hamburguesa en la línea delivery,

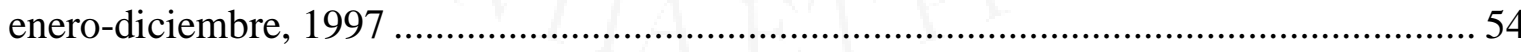

Figura 5.4 Número de comandas en la línea de delivery, enero-diciembre, 1997 .......... 55

Figura 5.5 Índice de insatisfacción del producto en la línea de delivery, enerodiciembre, 1997

Figura 5.6 Ventas por mes en la línea de delivery de Bembos, enero-diciembre, 1997. 57 


\section{ÍNDICE DE ANEXOS}

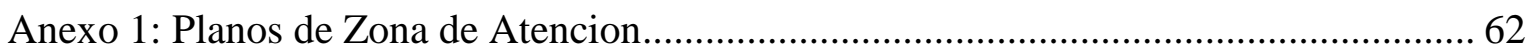

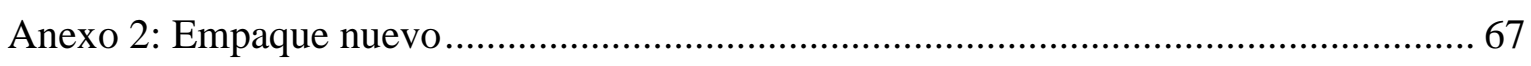




\section{RESUMEN EJECUTIVO}

La presente investigación es un estudio de Mejora de la Línea de Producción y Comercialización del Delivery de la empresa Bembos S.A.C (Bembos), llamada comercialmente como Rapid Bembos.

El estudio se llevó a cabo en abril de 1997, como responsable de la gerencia de finanzas, administración y planeamiento; se detectó que se venía presentando un creciente nivel de insatisfacción en el servicio del delivery a través del incremento de reclamos de los clientes mediante el canal de buzón de sugerencias que existían en todos los locales; y ello perjudicaba principalmente las ventas por delivery como el posicionamiento de la empresa en el mercado.

Este nivel de insatisfacción se generaba en mayor medida porque el producto principal, la hamburguesa, llegaba fría al destino de entrega en el delivery, por lo que se decidió analizar a detalle las causas y proponer soluciones para minimizar el índice de insatisfacción.

El índice de insatisfacción es una ratio compuesto por el nivel de reclamos sobre el número de comandas (pedidos). Este índice llegó a alcanzar valores de más de $14 \%$ en el primer trimestre del año, es decir que de cada 100 pedidos 14 estaban insatisfechos con el servicio de delivery.

Las causas que originaban un nivel alto de reclamos de los clientes en el servicio de delivery estaban concentrados principalmente en dos problemas: el producto hamburguesa llegaba frío y el no cumplimiento del tiempo total de atención de 30 minutos ofrecido por Bembos. Se llegaron a determinar las causas de estos problemas, las cuales era: demoras en cada parte del proceso de atención, error en el diseño del empaque, falta de un área especial de empaque, errores cometidos por el personal de la central que toma el pedido como la que realiza el empaque, y finalmente equipos y sistema obsoletos.

Siguiendo la herramienta de lluvia de ideas se desarrollaron las soluciones más óptimas, las mismas que fueron luego aplicadas logrando eliminar los problemas detectados y con ello se redujo el índice de insatisfacción a niveles mínimos, pasando de un promedio de $12,88 \%$ en los primeros cuatro meses, a menos del $1 \%$ en el último mes del año. 
Así también, luego de la aplicación de las soluciones de mejora se incrementaron los niveles de ventas en un $37 \%$, alcanzando la línea de delivery un mayor nivel de contribución en los ingresos de la cadena.

Los niveles de reclamos del producto hamburguesa se minimizaron llegando, al cierre del año, 7 meses de la aplicación de las mejoras, a reducirse en aproximadamente un $86 \%$ con respecto a enero del mismo año.

El número de comandas (pedidos) al mes se incrementó en un poco más de 40\%, al cierre del año de la investigación.

Otro tema que se logró mejorar con las soluciones aplicadas fue el del tiempo total de atención, para lo cual además fue necesario modificar el alcance de la zona de atención del delivery para algunos locales. Con ello los tiempos totales de atención se corrigieron logrando llegar al máximo de 30 minutos en todos los locales de la cadena.

Palabras clave: Reclamos, satisfacción, calidad, delivery y proceso. 


\section{EXECUTIVE SUMMARY}

The present investigation is an improvement study of the Production and Commercialization of the Delivery Line Delivery for the company Bembos S.A.C (Bembos), commercially called Rapid Bembos.

The study was carried out in July 1997. As Head of Finance, Administration and Management Planning; it was detected that there was a growing level of dissatisfaction in the delivery service through the increase in customer complaints in the suggestion box channel that existed in all the stores; and this mainly harmed the sales by delivery as well as the company's position in the market.

This level of dissatisfaction was generated to a greater extent because the main product, the hamburger, arrived cold at the delivery destination. It was then decided that we had to analyze the causes in detail and propose solutions to minimize the rate of dissatisfaction.

The dissatisfaction index is a ratio composed of the level of complaints over the number of orders. This index reached values of more than $14 \%$ in the first quarter of the year, meaning that in every 100 orders, 14 were dissatisfied with the delivery service.

The causes that generated a high level of customer complaints in the delivery service were mainly concentrated in two problems: the hamburger arrived cold and the non-fulfillment of the total time attention of 30 minutes offered by Bembos. The causes of these problems were determined: delays in each part of the service process, error in the design of the packaging, lack of a special packaging area, errors made by the plant personnel that took the order as well as the one that made the packaging, and finally obsolete equipment and system.

Following the brainstorming, the most optimal solutions were developed, the same ones that were then applied, eliminating the problems detected and thereby reducing the dissatisfaction rate to minimum levels, going from an average of $12,88 \%$ in the first four months, to less than $1 \%$ in the last month of the year.

Likewise, after the application of the improvement solutions, sales levels increased by $37 \%$, reaching the delivery line a higher level of contribution to the chain's revenues. 
The claims' levels of the hamburger were minimized at the end of the year, after 7 months of the improvements' applications, to be reduced by approximately $86 \%$ compared to January of the same year.

The number of orders per month increased by a little more than $40 \%$, at the end of the year of the investigation.

Another issue that was improved with the solutions applied was the total attention time, for which it was also necessary to modify the scope of the delivery service area for some stores. With this, the total attention times were corrected, reaching a maximum of 30 minutes in all the chain stores.

Keywords: Claims, satisfaction, quality, delivery y process. 


\section{CAPÍTULO I: ANTECEDENTES DE LA EMPRESA}

\subsection{Breve descripción de la empresa y reseña histórica.}

Bembos es una empresa peruana de Fast Food (comida rápida) que fue fundada el 18 de junio del 1988 con más de 30 años de presencia en el mercado. Su producto principal ha sido y es la hamburguesa en distintas presentaciones.

Desde sus inicios tuvieron como objetivo ser líderes en su segmento, y para ello se trazaron la premisa de mantener su posicionamiento en una línea de producto: el de hamburguesas, sin caer en la diversificación de productos como estrategia de lograr más participación en el mercado.

La estrategia de crecimiento requirió de respetar el formato arquitectónico a fin de permitir una rápida identificación de los locales de la cadena, tal como se aprecia en la Figura 1.1, innovando con modernos locales como aquellos que existían en las principales ciudades del mundo, así como de una fuerte creatividad en la creación de más productos, afinados al sentir y gustos del paladar peruano que, junto con en el diseño de promociones, lograran anticiparse a sus competidores.

Figura 1.1

Ejemplo de diseño de un local de Bembos

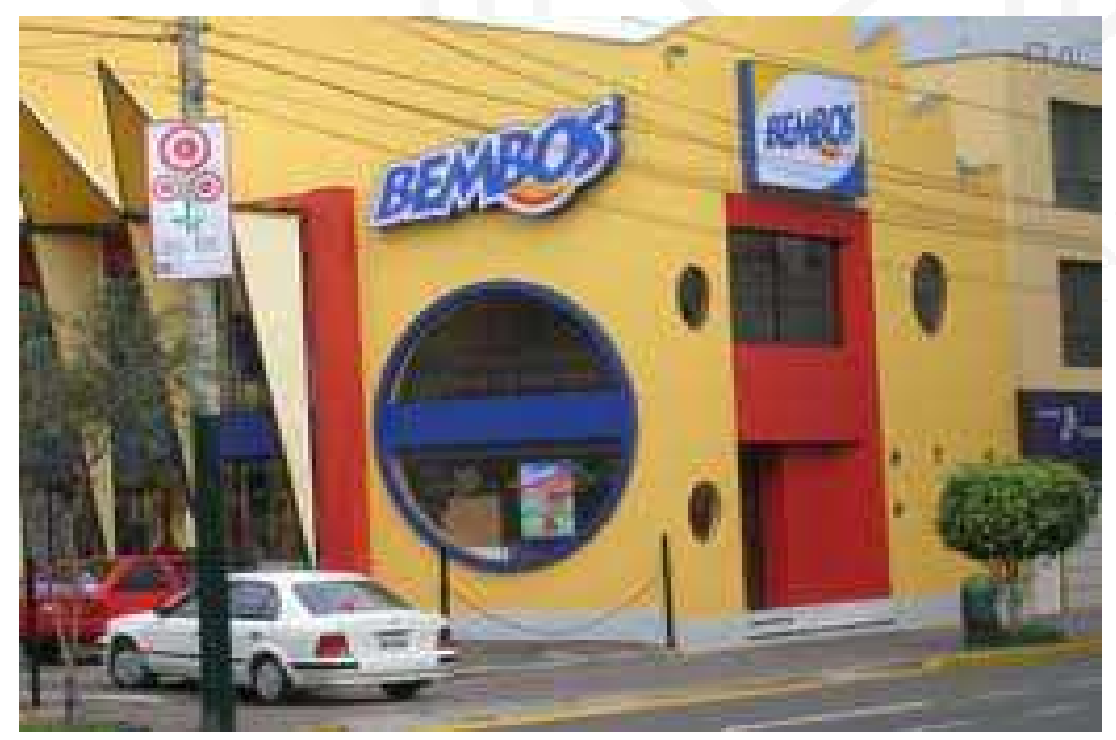

Fuente: Imágenes en Google (2019) 
Además, de crear un ambiente divertido, de moderna decoración, tal como se aprecia en la Figura 1.2, junto con un producto y un servicio de muy alta satisfacción, generándose, como resultado del proceso, una gran acogida en el mercado.

\section{Figura 1.2}

Ejemplo de decoración de ambientes en los locales de Bembos

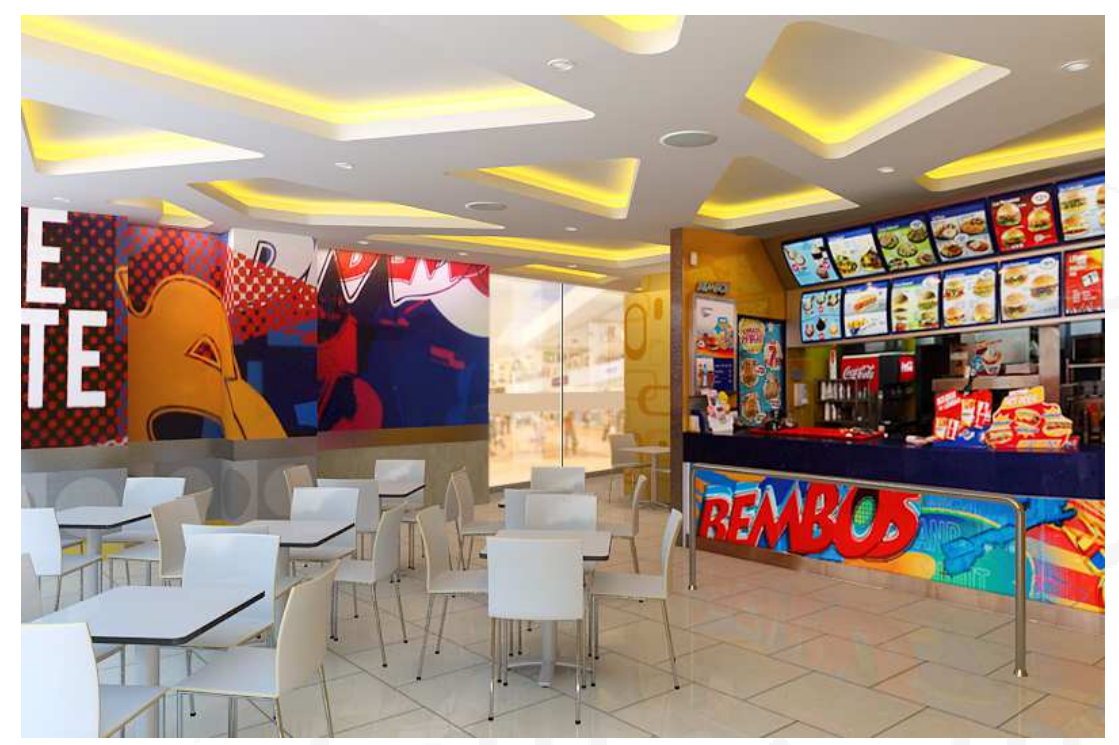

Fuente: Imágenes en Google (2019)

La historia de la empresa se inició en un entorno difícil debido a las condiciones políticas y socioeconómicas de aquella época como fueron: el terrorismo y la hiperinflación. El primer local de la cadena se ubicó en el distrito de Miraflores, y recién, dos años después de su creación, por el año 1990, se expande a un segundo local, en el mismo distrito, debido a que el país logró recién estabilizar su economía presentándose las condiciones favorables para expandirse.

Además, los consumidores reclamaban la apertura de más locales y así la empresa asumió un esfuerzo considerable, tanto en lo financiero como en la organización y formación de cuadros de colaboradores, a fin de mantener la calidad de acuerdo con las expectativas de los clientes.

El análisis del mercado de comidas rápidas, que realizaron en ese tiempo, les permitió darse cuenta de que había campo para expandirse e innovar, y es así trazan todo un plan de crecimiento que los lleva a tener: 2 locales en 1990, 4 para 1992, 8 para 1995 y 13 para 1997 (fecha del estudio). 
Solo algunos de los locales contaban con áreas de juegos para niños, servicio delivery (servicio de entrega al domicilio) y drive-thru (servicio de atención directa al auto).

Los locales en los que se desarrollaba el servicio de delivery eran nueve (9) de los trece (13) que en ese entonces tenía la cadena. En la tabla 1.1 se aprecian la lista de estos locales.

Tabla 1.1

Listado de locales que ofrecían el servicio de delivery en Bembos, 1997

\begin{tabular}{|l|l|l|l|}
\hline Nombre Comercial & $\begin{array}{l}\text { Categoria } \\
\text { tamaño }\end{array}$ & Direccion & Distrito \\
\hline Benavides & Mediano & Av Benavides 410 & Miraflores \\
\hline Dasso & Mediano & Av. Miguel Dasso & San Isidro \\
\hline Monterrico & Grande & Av. Primavera 1701 & Surco \\
\hline Aurora & Grande & Av. Benavides 1821 & Miraflores \\
\hline San Miguel & Grande & Centro Comercial Plaza San Miguel & San Miguel \\
\hline San Borja & Grande & Centro Comercial San Borja & San Borja \\
\hline Aramburu & Pequeño & Av. Andres Aramburu 390 & Miraflores \\
\hline La Molina & Grande & Av. Raul Ferrero 1400 & La Molina \\
\hline Gardenias & Grande & Av. Benavides 5350 & Surco \\
\hline
\end{tabular}

Elaboración propia

Adelantándose al concepto de gobierno corporativo, en el año 1996, los fundadores conforman un nuevo equipo gerencial, compuesto por un grupo de profesionales, especialistas cada uno en su campo, encargado de cada una de las áreas estratégicas de la empresa. Es bajo este esquema de gobierno corporativo, que se crea un comité especial que lo integraban los accionistas (2) y los gerentes de área (4), al que se le conocía como: comité de dirección y gestión, en el que se analizaban y debatían las estrategias de gestión y resultados de la empresa. Del cual forme parte al ser responsable de la gerencia de finanzas, administración y planeamiento.

Una de las primeras recomendaciones que realizó este comité fue el que se conformaran círculos de calidad para la mejora e innovación en las distintas áreas de la empresa.

El crecimiento de la cadena no solo llevo a más locales sino también a innovar y modificar los procesos internos, teniendo como condición fundamental para seguir 
creciendo el de la estandarización de todas las etapas del proceso productivo y lograr una calidad homogénea en cualquiera de los puntos de venta. Es así como en 1993 deciden tener una planta central, procesadora de insumos, y de esta forma lograr la uniformidad del producto, controlar los costos, la calidad de los ingredientes, así como alcanzar economías de escala, dejando en los locales solo la responsabilidad final de la elaboración, básicamente cocción, y ensamblaje (armado) de los productos.

Figura 1.3

Planta central de fabricación de productos de Bembos

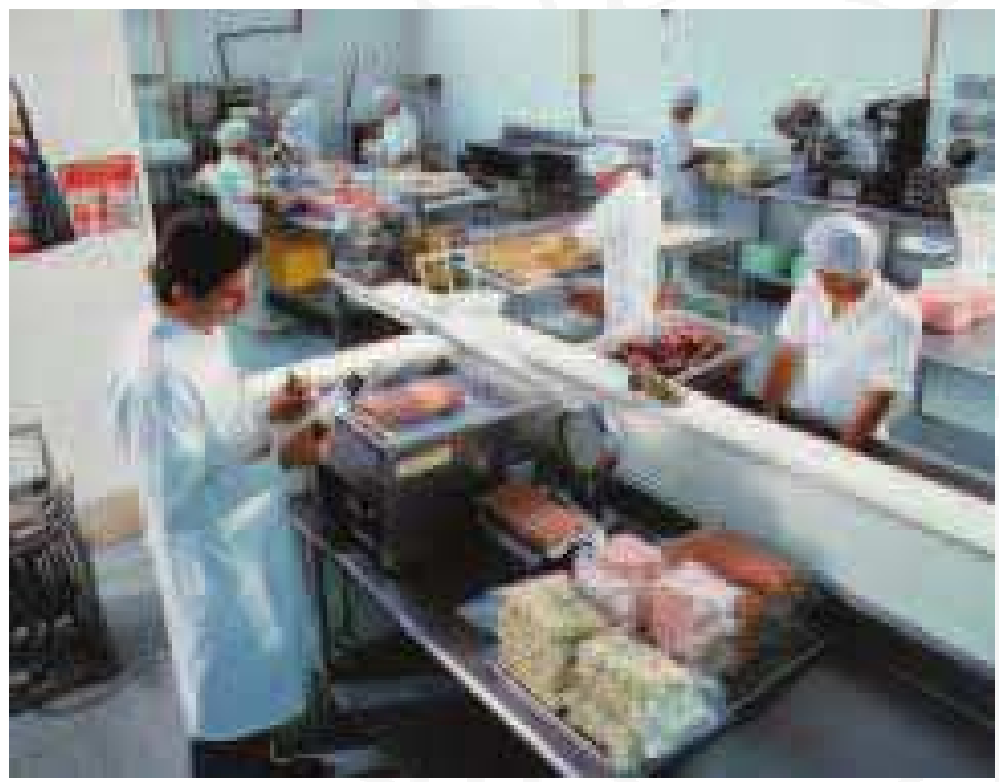

Fuente: Imágenes Google (2019)

La planta central, ubicada en el Parque Industrial San Pedrito, distrito de Surco, demandó una inversión financiera importante. Se implementó con la mejor tecnología disponible en aquel entonces, cuidando sobre todo los aspectos de:

- Condiciones higiénicas de manipulación de alimentos.

- Garantía de bioseguridad asegurando la cadena de frío en todo el proceso.

- Garantía de ausencia de carga bacteriana del producto hasta su destino final.

Junto con la implementación de la planta central se dio la selección más exhaustiva de los proveedores, buscando la estandarización de los insumos con la más alta calidad. Así también, fue necesario desarrollar un programa más eficiente de almacenamiento, en 
planta como en los locales, así como, un sistema logístico que asegure el abastecimiento oportuno y en condiciones eficientes.

Otra de las estrategias que se desarrollaron fueron programas de fidelización que buscaron premiar la lealtad del cliente, siendo indispensable estar en constante comunicación con ellos, para lo cual se creó el área de servicio al cliente que reportaba directamente a la gerencia general y al directorio, algo que, para la época, 1997, no era visto ni muy aceptado en el organigrama empresarial.

\subsubsection{Visión, misión y objetivos organizacionales.}

- Visión

Ser los primeros en el mercado, posicionándonos en la mente de nuestro grupo objetivo, como la organización con mejor calidad de producto y servicio a través de una adecuada estrategia flexible a las influencias del entorno.

\section{- Misión}

El compromiso central de Bembos es la satisfacción de las necesidades y expectativas de los clientes, en la medida de lo posible, brindándole una atención de calidad, garantizando nuestra eficacia para mantenernos en el tiempo como líderes de servicio y rentabilidad.

\section{- Objetivos organizacionales}

\section{○ Procesos internos:}

- Mejorar la infraestructura y potenciar el desarrollo tecnológico del servicio con la finalidad de cumplir con liderar el cambio mediante la innovación.

- Desarrollar una organización moderna que permita realizar los procesos de gestión y producción con eficiencia y eficacia.

\section{○ Aprendizaje:}

- Mantener un equipo humano de colaboradores feliz con orientación a los clientes. 


\section{○ Financiero:}

- Lograr niveles de rentabilidad que permitan el sostenimiento de la empresa y el desarrollo de tecnología que diferencia a la empresa.

\section{○ Clientes:}

- Superar los estándares de calidad de los clientes en su experiencia con el binomio: producto-servicio.

\section{○ Sociedad:}

- Responsabilidad social, sirviendo a la sociedad y respetado el medio ambiente.

- Integridad en todo el accionar de los directivos, gerentes y personal

\subsubsection{Descripción de los productos.}

\subsubsection{La hamburguesa}

El producto principal que ofrece la cadena se le denomina hamburguesa. Si bien la hamburguesa por definición es carne picada, condimentada generalmente con sal, pimienta y otras especies, que suele freírse o asarse; el producto principal que ofrece Bembos como las otras cadenas en el mercado mundial, es un sándwich de hamburguesa, con un pan blando y redondo al que se le suelen añadir otros ingredientes o condimentos, como: tomate, lechuga, queso, kétchup, mayonesa, entre otros; llamado así por su insumo principal: la hamburguesa.

En Bembos, esta hamburguesa es desarrollada, por estrategia, con un estilo diferencial de sabor y tamaño, lo que se conoce como: sabor peruano.

Existían varias presentaciones de la hamburguesa dependiendo de los insumos que la componen, pero todas tenían en común los siguientes insumos, considerados principales: Carne de ganado vacuno y pan. 
Figura 1.4

Hamburguesa Clásica de Bembos

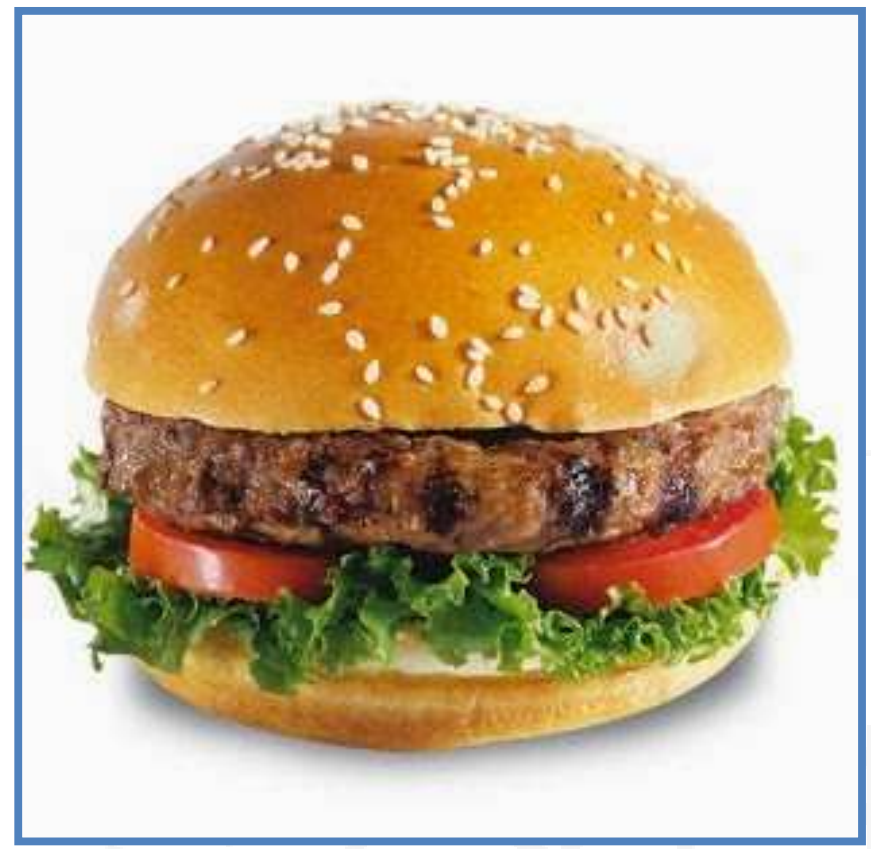

Fuente: Imágenes Google. (2019)

Así también, dentro de la misma presentación, existían tres tamaños del producto hamburguesa, todos en función del peso de la cantidad de hamburguesa en el sándwich. En la Tabla 1.2 se presentan los tres tamaños de hamburguesas.

Tabla 1.2

Tamaños de hamburguesas en Bembos, 1997

\begin{tabular}{|l|c|}
\hline $\begin{array}{l}\text { Nombre } \\
\text { tamaño }\end{array}$ & $\begin{array}{l}\text { Peso } \\
\text { hamburguesa }\end{array}$ \\
\hline Grande & $120 \mathrm{~g}$ \\
\hline Mediana & $100 \mathrm{~g}$ \\
\hline Chica & $80 \mathrm{~g}$ \\
\hline Promedio & $100 \mathrm{~g}$ \\
\hline
\end{tabular}

Fuente: Bembos S.A.C., (1997)

Elaboración propia

No todas las variedades de hamburguesas se ofrecían en los tres tamaños. Además de la hamburguesa, Bembos ofrecía otros productos que eran principalmente acompañamientos del producto principal. 
Los productos que ofrecía Bembos en el momento de la investigación se muestran en la Tabla 1.3.

Tabla 1.3

Listado de productos generales ofrecidos por Bembos, 1997

\begin{tabular}{|c|c|c|c|c|c|}
\hline Nombre & Tipo & Ingredientes & Cantidad & Abastecimiento & $\begin{array}{l}\text { Proceso general de } \\
\text { preparación }\end{array}$ \\
\hline \multirow{3}{*}{ Hamburguesa } & \multirow{3}{*}{ Sandwich } & Pan & 1 unidad & Proveedor & $\begin{array}{l}\text { Ligeramente tostado en } \\
\text { plancha. }\end{array}$ \\
\hline & & $\begin{array}{l}\text { Carne importada especial } \\
\text { de novillo bebe ( } 2 \text { o } 3 \\
\text { dientes) y otros insumos, }\end{array}$ & $100 \mathrm{~g}$ & Fabricación interna & $\begin{array}{l}\text { Cocción en un mix entre gas } \\
\text { y carbón. }\end{array}$ \\
\hline & & Otros insumos. & & Proveedor & \\
\hline Papas fritas & $\begin{array}{l}\text { Pack de } \\
\text { Papas fritas }\end{array}$ & Papa blanca importada. & $180 \mathrm{~g}$ & Fabricación interna & Cocción en aceite vegetal. \\
\hline Gaseosa & Gaseosa & & $500 \mathrm{ml}$ & Proveedor & \\
\hline Jugo & Jugos & Chicha morada. & $320 \mathrm{ml}$ & Proveedor & \\
\hline Helados & Helados & Vainilla o chocolate. & & Fabricación interna & $\begin{array}{l}\text { Elaborados por una } \\
\text { máquina especial. }\end{array}$ \\
\hline $\begin{array}{l}\text { Cheese } \\
\text { Fingers }\end{array}$ & Piqueo & $\begin{array}{l}\text { Palitos de harina rellenos } \\
\text { de queso }\end{array}$ & 6 unidades & Fabricación interna & Cocción en aceite vegetal. \\
\hline Postres & Postres & Varios & & Proveedor & Adquiridos de terceros \\
\hline
\end{tabular}

Fuente: Bembos S.A.C., (1997)

Elaboración propia

Estos podían ofrecerse de manera individual o en grupo, denominándose a la oferta grupal: combo, tal como se muestra en la Figura 1.5. 
Figura 1.5

Ejemplo de un combo en la oferta de Bembos

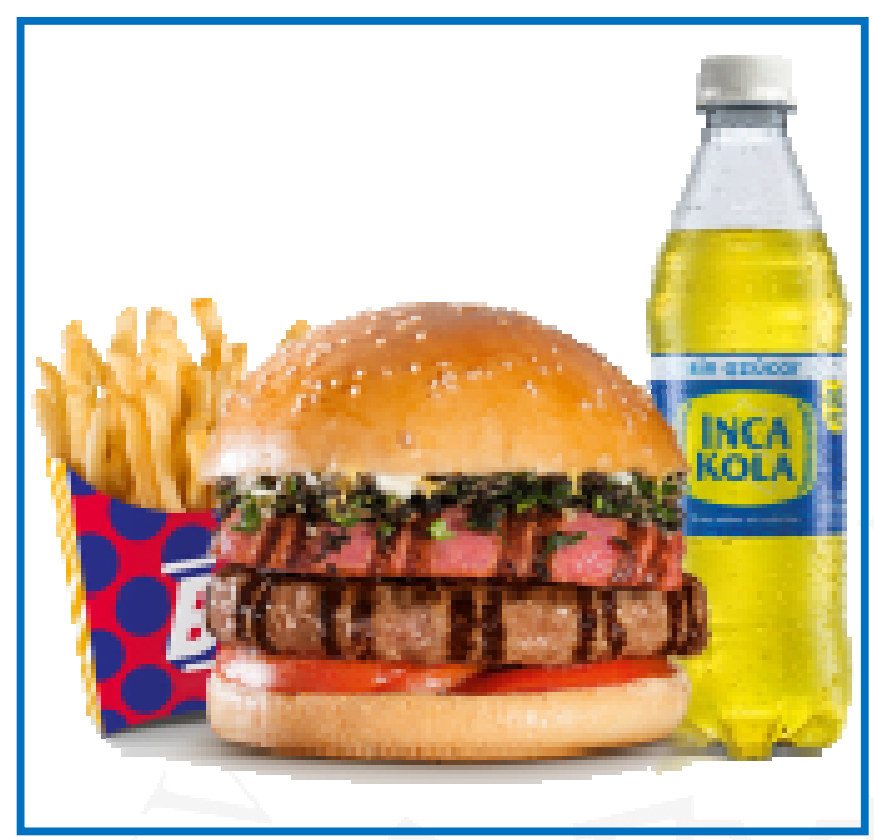

Fuente: Imágenes Google. (2019)

\subsubsection{Las papas fritas}

Las papas fritas era el segundo producto principal de la cadena, que participaba a lado de la hamburguesa en casi todos los combos, y a pesar de ser un complemento o acompañamiento de la hamburguesa, había ganado cierto protagonismo al punto que era pedida muchas veces sola.

Al igual que la hamburguesa, las papas fritas se ofrecían también en tres tamaños. En la Tabla 1.4 se presentan los tamaños y su peso.

Tabla 1.4

Tamaños de la oferta de papas fritas en Bembos, 1997

\begin{tabular}{|l|c|}
\hline $\begin{array}{l}\text { Nombre } \\
\text { tamaño }\end{array}$ & Peso papas \\
\hline Grande & $225 \mathrm{~g}$ \\
\hline Mediana & $175 \mathrm{~g}$ \\
\hline Regular & $80 \mathrm{~g}$ \\
\hline Promedio & $160 \mathrm{~g}$ \\
\hline
\end{tabular}

Fuente: Bembos S.A.C., (1997)

Elaboración propia 
Los canales de venta y entrega de los productos eran dos: los locales y el delivery. Considerando a ambos como dos líneas de negocio separadas que compartían la fase de producción en el proceso.

En la Tabla 1.5 se puede apreciar los precios promedio de cada uno se los productos ofrecidos, así como su costo promedio.

Tabla 1.5

Precios y costos promedio por producto, 1997

\begin{tabular}{|l|c|c|c|l|}
\hline Hamburguesa & 10,00 & 3,50 & 0,35 & Bols a plás tica con logo. \\
\hline Pack Papas fritas & 3,50 & 1,25 & 0,30 & Envase de cartón \\
\hline Gaseosa & 3,50 & 1,25 & 0,25 & Bols a de plástico con logo. \\
\hline Cheese Fingers & 8,00 & 2,75 & 0,30 & Caja de cartón. \\
\hline $\begin{array}{l}\text { Bolsa empaque } \\
\text { delivery }\end{array}$ & & & $\begin{array}{l}\text { Bols a de papel de } 50 \\
\text { gramos. }\end{array}$ \\
\hline
\end{tabular}

Fuente: Bembos S.A.C., (1997)

Elaboración propia

En la Tabla 1.6 se presenta la estructura del margen bruto promedio, en soles, de una unidad de producto hamburguesa, por delivery, al momento del estudio, y en ella se puede apreciar que el costo del producto hamburguesa, antes de la mejora propuesta en esta investigación, era de 37,50\% del precio de venta, siendo el margen bruto del 62,50\%.

Tabla 1.6

Margen bruto unitario en soles del producto hamburguesa en Bembos, 1997

\begin{tabular}{|l|c|l|}
\hline & Valor (S/.) & Observaciones \\
\hline Precio Venta & 10,00 & \\
\hline $\begin{array}{l}\text { Costo sin } \\
\text { Empaque }\end{array}$ & 3,50 & \\
\hline Costo Empaque & 0,25 & $\begin{array}{l}\text { Sobre de papel } \\
\text { con logo. }\end{array}$ \\
\hline Margen Bruto & 6,25 & \\
\hline
\end{tabular}

Fuente: Bembos S.A.C., (1997)

Elaboración propia

En la Tabla 1.7 se presenta la estructura del margen bruto promedio, en soles, de una unidad de producto papas fritas al momento del estudio. Al momento del estudio el 
costo del producto papas fritas llegaba al $48,60 \%$ de su precio de venta, siendo el margen bruto de $51,40 \%$.

\section{Tabla 1.7}

Margen bruto unitario en soles del producto papas fritas en Bembos, 1997

\begin{tabular}{|l|c|l|}
\hline & Valor (S/.) & Observaciones \\
\hline Precio Venta & 3,50 & \\
\hline $\begin{array}{l}\text { Costo sin } \\
\text { Empaque }\end{array}$ & 1,50 & \\
\hline Costo Empaque & 0,30 & $\begin{array}{l}\text { Envase de } \\
\text { cartón }\end{array}$ \\
\hline Margen Bruto & 1,70 & \\
\hline
\end{tabular}

Fuente: Bembos S.A.C., (1997)

Elaboración propia

\subsubsection{Descripción del servicio de delivery}

El servicio de delivery de Bembos se creó bajo el nombre de Rapid Bembos en 1994, y en el momento del proyecto, 1997, tenía 4 años de funcionamiento en Lima. Cuando se inició sólo dos locales ofrecían el servicio, para luego, periódicamente, ir implementándolo en algunos locales más.

Este servicio permite que numerosas personas puedan disfrutar de los productos en sus hogares, oficinas o en otro lugar distinto del local de bembos.

En la Figura 1.6 se muestra el flujo del proceso de atención de la línea delivery. 
Figura 1.6

Flujo del proceso de atención del delivery en Bembos, 1997

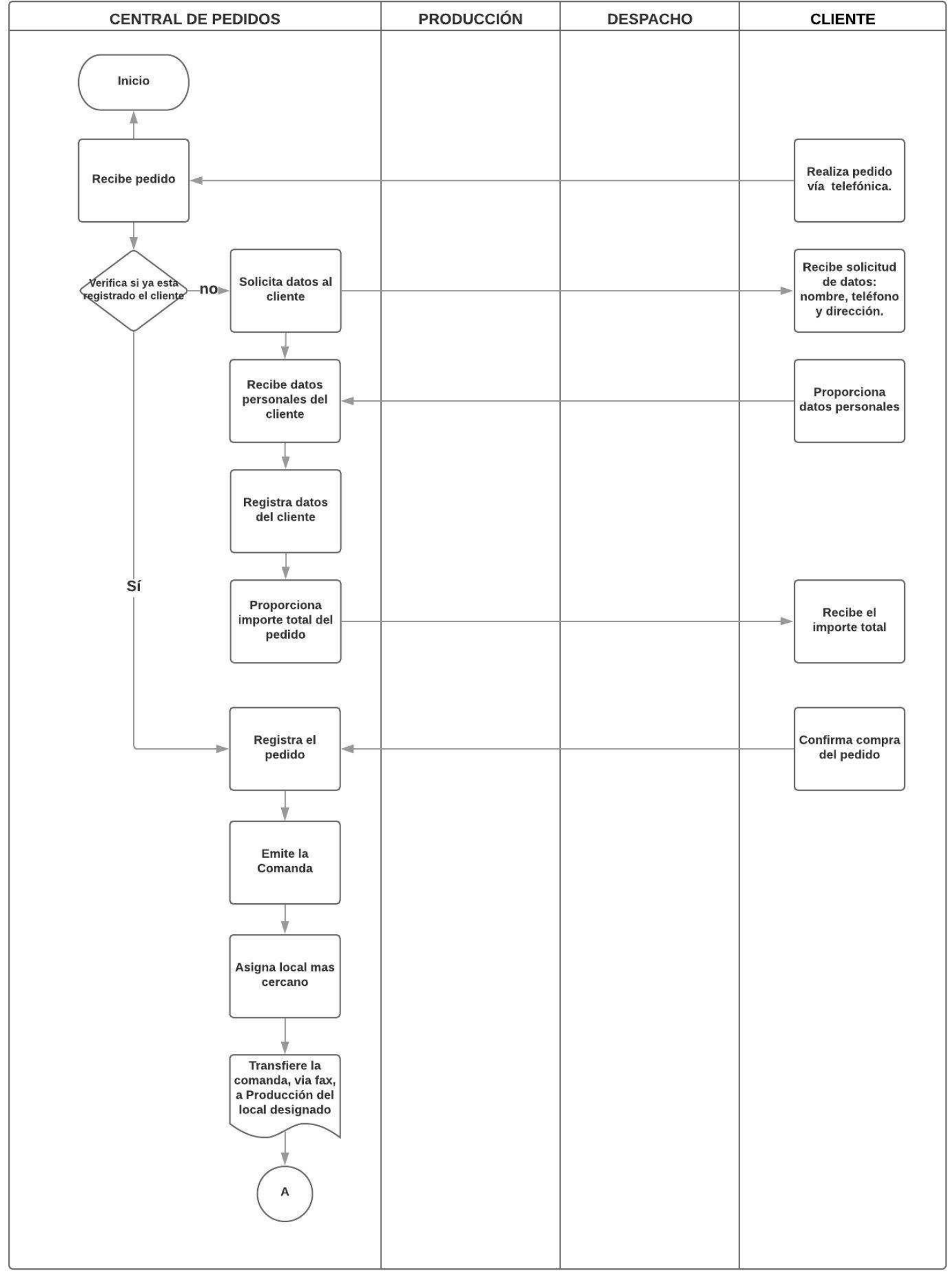

(continúa) 
(continuación)

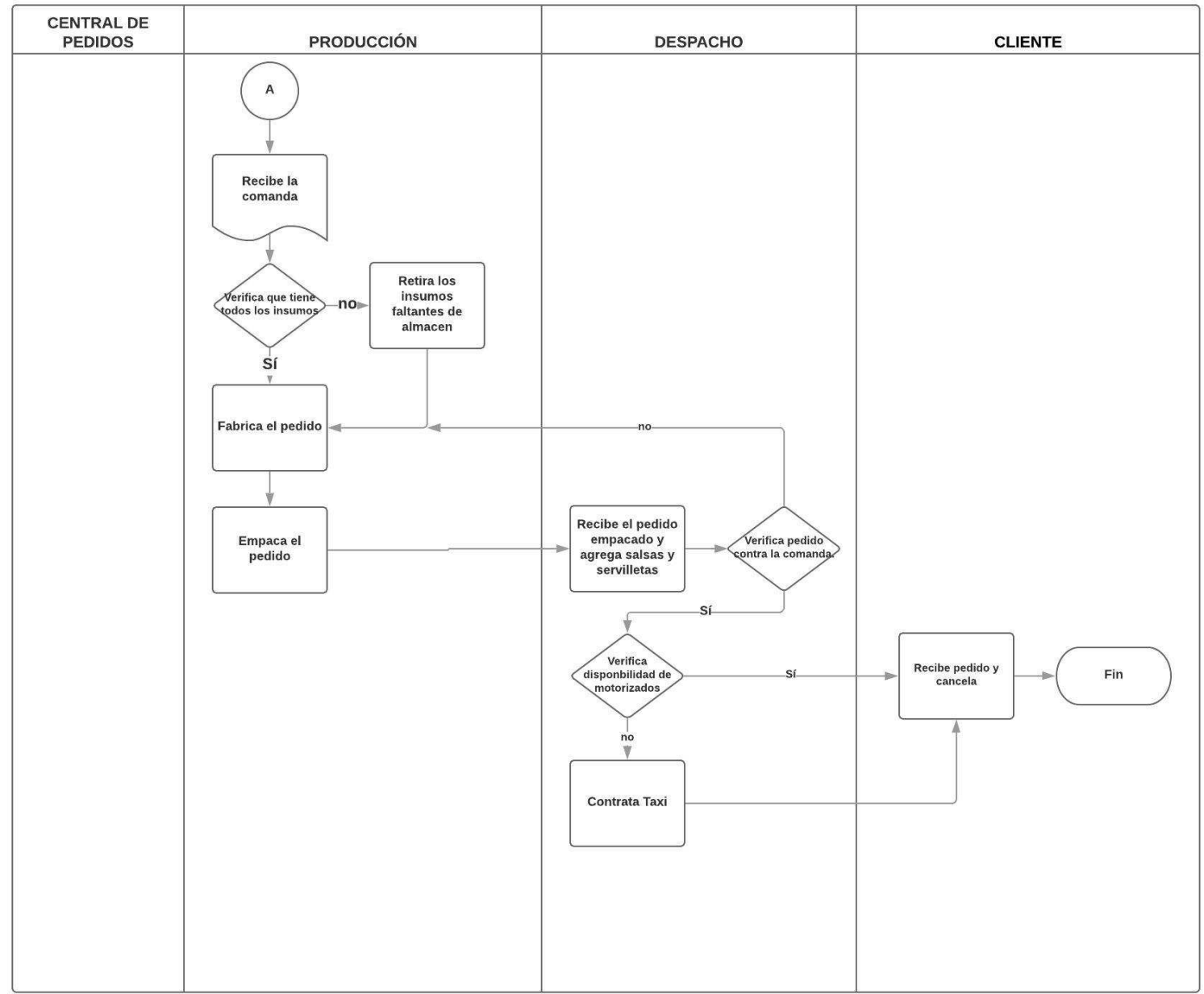

Elaboración propia

Rapid Bembos contaba con una central de pedidos ubicada en el segundo piso de uno de los locales de la cadena, específicamente en el local de Monterrico, donde se recibían las llamadas telefónicas de los clientes. Estos, con una simple llamada, hacían sus pedidos y se les enviaba lo requerido.

La Central se encargaba de asignar la atención de los diferentes pedidos a los locales que participaban en esta red de servicio de acuerdo con su ubicación y cercanía con la dirección del pedido.

Los locales no podían tomar pedidos directamente, tanto porque existía un solo número telefónico comunicado a los clientes para brindar este servicio.

Los locales en los que se desarrollaba el servicio eran nueve (9) de los trece (13) que en ese entonces tenía la Cadena, tal como se presentó en la Tabla 1.1. 


\subsubsection{Mercado objetivo}

Bembos tenía definido como mercado objetivo para la línea de servicio de delivery a los segmentos: medio, medio alto y alto, en los distritos donde se realizaba el reparto desde sus locales; ello debido al ticket promedio de la Cadena (USD7,00) en relación a los ingresos promedio familiares, dándose el mayor número de pedidos en esos segmentos.

En la Tabla 1.8 se puede apreciar los tickets promedio de la cadena por local donde se brinda el servicio de delivery.

Tabla 1.8

Ticket promedio de venta soles en delivery por local, enero-abril, 1997

\begin{tabular}{|l|c|c|c|c|}
\hline & ENERO & FEBRERO & MARZO & ABRIL \\
\hline \multicolumn{1}{|c|}{ TIENDA } & Prom. x Com. & Prom. x Com. & Prom. x Com. & Prom. x Com. \\
\hline Benavides & 34,50 & 36,38 & 35,26 & 35,32 \\
\hline Dasso & 37,06 & 37,06 & 35,74 & 35,10 \\
\hline Monterrico & 34,33 & 33,61 & 33,21 & 34,57 \\
\hline Aurora & 35,22 & 39,07 & 36,30 & 32,42 \\
\hline San Miguel & 39,84 & 39,04 & 39,12 & 39,19 \\
\hline San Borja & 35,52 & 36,85 & 36,01 & 33,60 \\
\hline Texaco-Aramburu & 24,58 & 22,55 & 22,76 & 18,75 \\
\hline La Molina & 37,67 & 35,08 & 35,98 & 36,11 \\
\hline Gardenias & 35,33 & 35,95 & 32,76 & 35,52 \\
\hline TOTAL RAPID & $\mathbf{3 5 , 8 1}$ & $\mathbf{3 6 , 1 3}$ & $\mathbf{4 0 , 3 7}$ & $\mathbf{3 5 , 6 8}$ \\
\hline
\end{tabular}

Fuente: Bembos S.A.C., (1997)

Elaboración propia

Se realizó el cálculo del tamaño de mercado por distrito para lo cual se obtuvo información del INEI.

En la Tabla 1.9 se presenta el número de hogares en los diferentes segmentos socioeconómicos objetivo en los distritos donde están ubicados los locales al momento de la investigación. 
Tabla 1.9

Número de hogares por distrito y nivel socioeconómico (NSE), 1997

\begin{tabular}{|l|r|rr|r|}
\hline & \multicolumn{3}{|c|}{ Estrato Socio-Económico } & \\
\hline Distrito & \multicolumn{1}{|c|}{ Medio } & Medio Alto & \multicolumn{1}{c|}{ Alto } & \multicolumn{1}{c|}{ Total } \\
\hline Miraflores & 4494 & 9515 & 4601 & $\mathbf{1 8 6 1 0}$ \\
\hline San Borja & 3298 & 9686 & 5226 & $\mathbf{1 8 2 1 0}$ \\
\hline San Isidro & 2338 & 7149 & 4965 & $\mathbf{1 4 4 5 2}$ \\
\hline San Miguel & 5561 & 8376 & 2421 & $\mathbf{1 6 3 5 8}$ \\
\hline La Molina & 1746 & 4974 & 4815 & $\mathbf{1 1 5 3 5}$ \\
\hline Santiago de Surco & 6825 & 14900 & 9042 & $\mathbf{3 0 7 6 7}$ \\
\hline Total & $\mathbf{2 4 2 6 2}$ & $\mathbf{5 4 6 0 0}$ & $\mathbf{3 1 0 7 0}$ & $\mathbf{1 0 9} \mathbf{9 3 2}$ \\
\hline
\end{tabular}

Fuente: Instituto Nacional de Estadística e Informática, INEI (1997).

A continuación, en la Tabla 1.10 se muestran las características los segmentos: Alto, Medio Alto y Medio.

Tabla 1.10

Características de los niveles socioeconómicos: alto, medio alto y medio, 1997.

\begin{tabular}{|c|c|}
\hline NSE & Características \\
\hline \multirow{7}{*}{ Alto } & Autopercepción de la clase social media/alta. \\
\hline & Educación del jefe de hogar: superior universitaria/postgrado. \\
\hline & Colegio de los hijos: privado. \\
\hline & Ocupación del jefe de hogar: empresarios/gerentes. \\
\hline & Ingreso mensual ordinario promedio: mas de USD5 000. \\
\hline & Ingreso mensual ordinario mediana: mas de USD5 000. \\
\hline & Zona de residencia: residencial. \\
\hline \multirow{7}{*}{ Medio alto } & Autopercepción de la clase social media. \\
\hline & Educación del jefe de hogar: superior universitaria. \\
\hline & Colegio de los hijos: privado. \\
\hline & Ocupación del jefe de hogar: profesionales independientes o dependientes. \\
\hline & Ingreso mensual ordinario promedio: mas de USD3 500. \\
\hline & Ingreso mensual ordinario mediana: mas de USD2 700 \\
\hline & Zona de residencia: residencial. \\
\hline \multirow{7}{*}{ Medio } & Autopercepción de la clase social media. \\
\hline & Educación del jefe de hogar: superior universitaria. \\
\hline & Colegio de los hijos: privado. \\
\hline & Ocupación del jefe de hogar: ejecutivos/profesionales independientes. \\
\hline & Ingreso mensual ordinario promedio: mas de USD1 300. \\
\hline & Ingreso mensual ordinario mediana: mas de USD950. \\
\hline & Zona de residencia: media. \\
\hline
\end{tabular}

Fuente: Instituto Nacional de Estadística e Informática, INEI (1997). 


\subsubsection{Ventas y estados financieros}

\subsubsection{Ventas y estados financieros de la empresa}

En la figura 1.7 se muestran las ventas de Bembos desde el año en que se desarrolló el estudio, 1997, al 2001.

\section{Figura 1.7}

Ventas totales anuales en soles, 1997-2001.

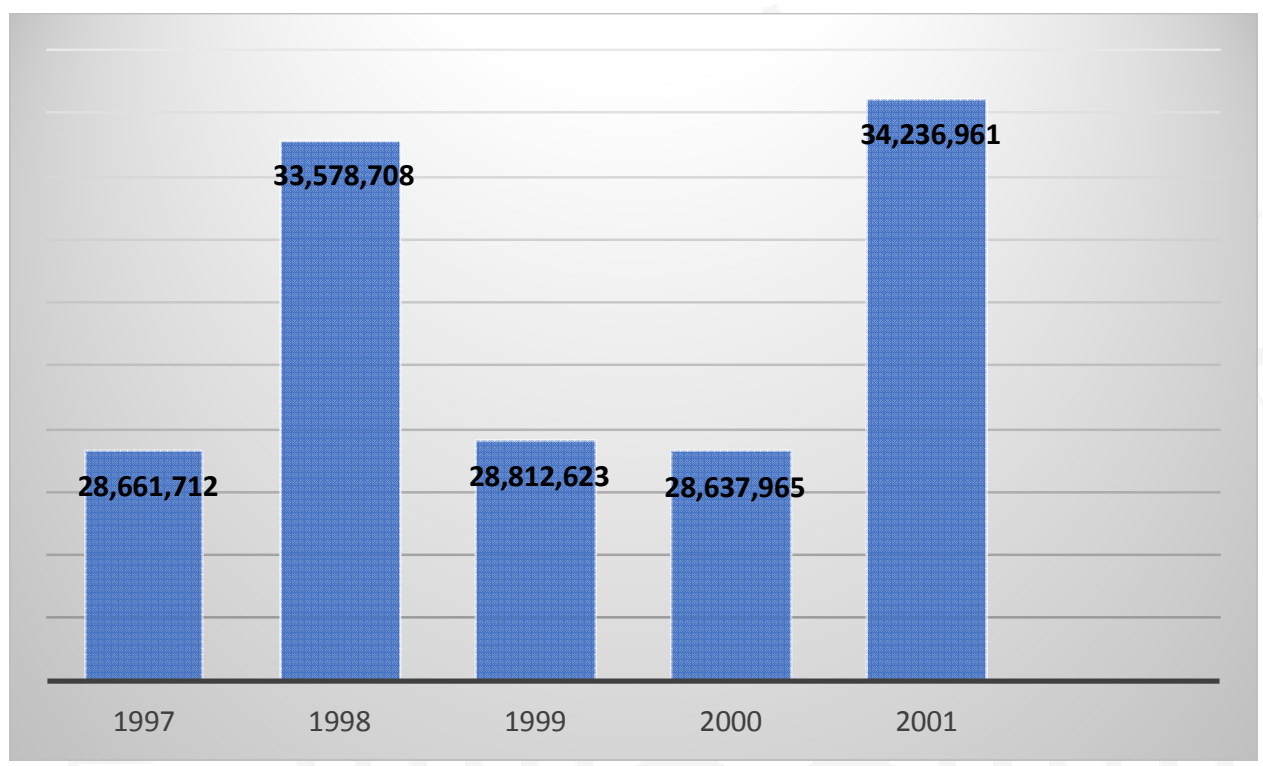

Fuente: Bembos S.A.C., (1997)

Elaboración propia

Podemos apreciar que en 1997 se cerró con S/.28 661712 y en 1998 se logró un incremento del 17\% para luego caer en el 1999 en un 14\%. En el 2001 las ventas se mantuvieron con respecto a 1999. Luego, en 2001, se logra una recuperación a niveles superiores al de 1998.

Es importante mencionar que en el 1999 se vivía una situación política muy complicada con anuncios como la tercera reelección del presidente Fujimori, como también en el aspecto económico, que se inició con los efectos climatológicos del fuerte Fenómeno del Niño, cuyos efectos se sintieron a partir de marzo de 1997 y se prolongaron hasta mediados de 1998), luego con la crisis económica y financiera internacional de 19971999, la cual se inició con la crisis asiática para extenderse al resto de los mercados financieros, afectando a los mercados de las economías emergentes y en desarrollo.

Los resultados de Bembos se vieron afectados por este entorno complicado alcanzando los resultados financieros que se muestran en la Tabla 1.11. 
Tabla 1.11

Principales cifras financieras de Bembos, 1997-2001

\begin{tabular}{|l|c|c|c|c|c|}
\hline \multicolumn{7}{|c|}{ Estado de Ganancias y Pérdidas (soles) } \\
\hline Nombre & $\mathbf{1 9 9 7}$ & $\mathbf{1 9 9 8}$ & $\mathbf{1 9 9 9}$ & $\mathbf{2 0 0 0}$ & $\mathbf{2 0 0 1}$ \\
\hline Ventas & 28661712 & 33578708 & 28812623 & 28637965 & 34236961 \\
\hline Costo de Ventas & 12832235 & 15425659 & 12935367 & 10994367 & 14714403 \\
\hline Utilidad Bruta & 15829477 & 18153049 & 15877256 & 17643598 & 19522558 \\
\hline Gastos de Operación & 13452060 & 14880380 & 14710257 & 15372010 & 14589987 \\
\hline Utilidad Operativa & 2377417 & 3272669 & 1166999 & 2271588 & 4932571 \\
\hline Impuestos y/o otros & 926987 & 3522277 & 3358891 & 1669162 & 1286295 \\
\hline Utilidad Neta & 1450430 & -249608 & -2191892 & 602426 & 3646276 \\
\hline
\end{tabular}

\begin{tabular}{|l|c|c|c|c|c|}
\hline \multicolumn{7}{|c|}{ Datos del Balance (soles) } \\
\hline Nombre & $\mathbf{1 9 9 7}$ & $\mathbf{1 9 9 8}$ & $\mathbf{1 9 9 9}$ & $\mathbf{2 0 0 0}$ & $\mathbf{2 0 0 1}$ \\
\hline Activo Total & 23529003 & 31105580 & 24008778 & 22412757 & 20912087 \\
\hline Pasivo Total & 18211144 & 26982359 & 19619081 & 17263168 & 9048537 \\
\hline Patrominio & 3800819 & 4123221 & 4389697 & 5149589 & 8795865 \\
\hline Ganancia diferida & 1517040 & & & & 3067685 \\
\hline
\end{tabular}

Fuente: "Compartiendo Experiencias", AMROP International y PAD Escuela de Dirección de la Universidad de Piura, (2002)

Elaboración propia

\subsubsection{Ventas por delivery}

En la Figura 1.8 se muestran las ventas totales por la línea de delivery en el periodo de enero a abril 1997, antes de la aplicación de las mejoras producto del presente estudio. 
Figura 1.8

Ventas en soles de la línea delivery Bembos, enero-abril, 1997

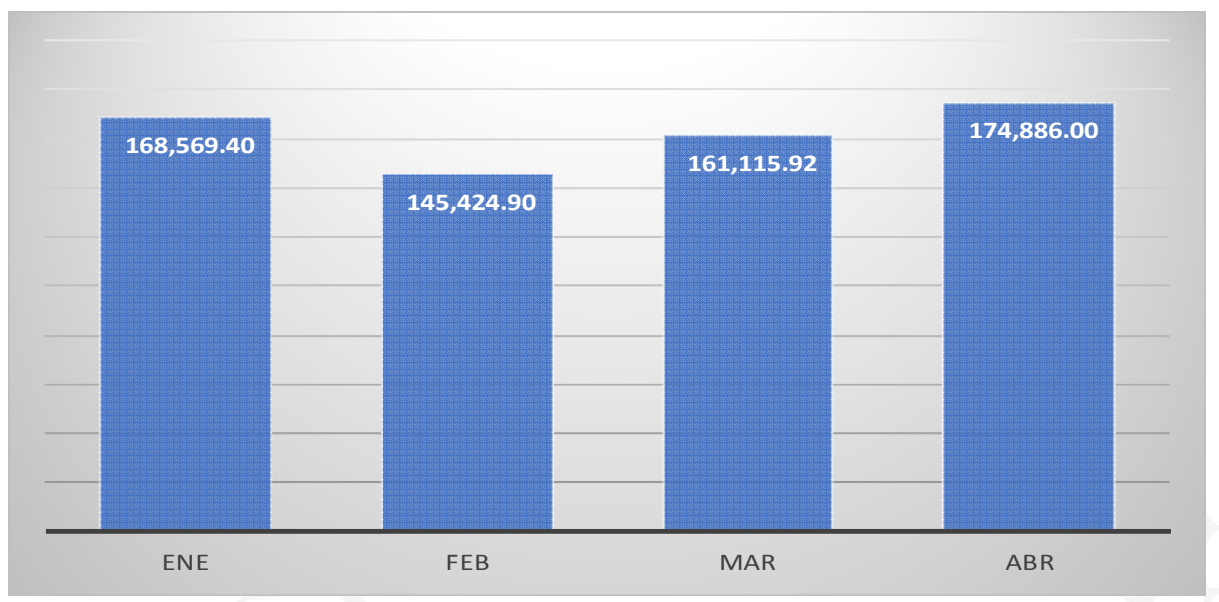

Fuente: Bembos S.A.C., (1997)

Elaboración propia

\subsection{Descripción del sector.}

Según el artículo: ¿Cuál es la Historia de la Comida rápida?, publicado por El Comercio el 11/10/2010), la historia de este género comienza a finales de 1800 con la invención de la máquina de picar carne, dando origen a la hamburguesa. Hasta inicios del siglo XX, indica El Comercio en su publicación, se consideraba que se trataba de una comida insegura y para los pobres.

En 1919, indica El Comercio, la cadena de restaurantes A\&W Root Beer, se presenta como el primer establecimiento en contar con una ventanilla de servicio para el auto. Es así que se daba comienzo a los primeros intentos de un servicio distinto al dado dentro de un local.

En la década de 1940, en el Perú, se ponen de moda los locales de atención al auto, con diseño y luces llamativas que lograron cautivar la atención de los clientes, siendo el caso más conocido el de la cadena Tip Top.

Hablar de comida rápida no es posible sin mencionar el caso del gigante McDonald's, que fue producto del impulso empresarial de los hermanos Richard y Maurice McDonald, quienes abrieron su primer local en 1949.

Es así que se da el nacimiento de un nuevo concepto de alimentación con lo cual el diccionario Merriam-Webster (editorial estadounidense que publica libros de referencia, sobre todo diccionarios) incluyó el término "comida rápida" en su publicación de 1951. 
La comida rápida tuvo un crecimiento explosivo en los próximos años de su nacimiento, y veinte años después se encontraba casi en todo el mundo. Un ejemplo de ello es que los fabricantes de autos modificaron los portavasos en sus diseños, agrandándolos, para que pudieran entrar los vasos de gaseosa más grandes.

La comida rápida en el Perú llegó en la década de los 80, en un momento político y económico muy difícil. Kentucky Fried Chicken (KFC), cadena transnacional americana, era la única oferta de comida rápida en el mercado peruano que operaba como franquicia. Luego, en 1983 aparece una segunda cadena transnacional americana de comida rápida, denominada Pizza Hut, también bajo la modalidad de franquicia, que ofrece pizzas bajo este concepto.

En la década de los 90 la competencia en el segmento de hamburguesas fue muy intensa, obligando a las cadenas a ser muy creativas en sus productos y campañas para defender sus posiciones en el mercado. Ello también impulsado por los cambios políticos y económicos favorables que se dieron en el país. El Perú abrió sus puertas a la inversión extranjera dentro la corriente de globalización que vivía el planeta, y después de cinco años de total aislamiento.

En 1993 hace su ingreso al Perú, bajo el esquema de franquicia, la cadena transnacional americana de hamburguesas Burger King (BK), considerada como la segunda más importante del mundo. Inmediatamente se coloca en frontal competencia al que en ese momento era la cadena nacional líder del mercado: Bembos.

Más adelante, con el ingreso de McDonald's, en 1996, los precios tuvieron un impacto inmediato hacia la baja, puesto que el gigante de la comida rápida ingreso con un esquema muy agresivo de precios bajos como su estrategia de penetración en el mercado peruano. Estrategia que era siempre su caballo de batalla de ingreso en todos los países donde ingresa. A eso se le sumaba el plan de expansión que de dicha cadena para estar presente en el más corto plazo los segmentos estratégicos de comensales.

Es así que, en corto tiempo, lanza 11 locales al mercado, y aprovechando en ser una gran alternativa alimenticia para los sectores populares, es que gana rápidamente una participación en el mercado.

Entre 1995 y 1999 aparecieron otras cadenas extranjeras y locales, que motivas por la oportunidad de expansión que ofrecía el Perú, como porque el ciudadano limeño, principalmente, le había encontrado el atractivo a la oferta de las comidas rápidas, se 
instalaban en el país: Dominos Pizza, Taco Bell, Miami Subs, Yogen Fruz, Chifast, Pasta Pronta, Mediterráneo Chicken, entre otras.

\subsubsection{Análisis de la competencia.}

Se realizó un seguimiento y comparación (Benchmarking) del servicio delivery en las principales cadenas que brindaban este canal. Ello con el propósito de conocer la oferta de los principales competidores.

Es importante tener en cuenta que, desde el punto de vista del producto principal ofrecido, la competencia de Bembos, al momento del estudio, se podía categorizar en dos tipos: competencia directa y competencia indirecta, tal como se muestra en la Tabla 1.12

Tabla 1.12

Competencia directa e indirecta de Bembos, 1997

\begin{tabular}{|l|c|l|c|}
\hline Cadena & Competencia & Venta & Matriz \\
\hline Burger King & Directa & Hamburgues as & Extranjera \\
\hline KFC & Indirecta & $\begin{array}{l}\text { Piezas de pollo } \\
\text { empanizadas }\end{array}$ & Extranjera \\
\hline Pizza Hut & Indirecta & Pizzas & Extranjera \\
\hline $\begin{array}{l}\text { Dominos } \\
\text { Pizza }\end{array}$ & Indirecta & Pizzas & Extranjera \\
\hline McDonalds & Directa & Hamburgues as & Extranjera \\
\hline Chifast & Indirecta & Chifa & Nacional \\
\hline Taco Bell & Indirecta & Tacos & Extranjera \\
\hline Pasta Pronta & Indirecta & Pastas & Extranjera \\
\hline $\begin{array}{l}\text { Mediterraneo } \\
\text { Chicken }\end{array}$ & Indirecta & Pollo a la braza & Nacional \\
\hline
\end{tabular}

Elaboración propia

Los considerados como competencia directa eran las empresas que ofrecían el producto de hamburguesa, y la competencia indirecta las que ofrecían otros productos alimenticios, pero siempre dentro del concepto de comida rápida.

En la Tabla 1.13 se muestran el esquema del servicio delivery que ofrecían, en la fecha del estudio, las principales cadenas de comida rápida en el país. 
Tabla 1.13

Oferta delivery de la competencia principal, 1977

\begin{tabular}{|c|c|c|c|c|c|c|}
\hline Cadena & \begin{tabular}{|l|} 
Número de \\
locales de \\
reparto \\
\end{tabular} & Dis tritos & Turnos & $\begin{array}{l}\text { Ticket promedio } \\
\text { (soles) }\end{array}$ & $\begin{array}{l}\text { Costo de } \\
\text { Envio } \\
\end{array}$ & $\begin{array}{l}\text { Tiempo máximo } \\
\text { de entrega }\end{array}$ \\
\hline \multirow[b]{2}{*}{ Bembos } & \multirow[b]{2}{*}{9} & \multirow{2}{*}{$\begin{array}{l}\text { Miraflores, San } \\
\text { Isidro,Surco, } \\
\text { San Borja, San } \\
\text { Miguel, La } \\
\text { Molina. }\end{array}$} & \multirow[b]{2}{*}{2} & $\begin{array}{l}\text {. Lunes a jueves: } 30,00 \\
\text { a } 35,00 \text {. }\end{array}$ & \multirow[b]{2}{*}{3,50} & \multirow[b]{2}{*}{30 minutos } \\
\hline & & & & $\begin{array}{l}\text { Sábado y domingo: } \\
30,00 \text { a } 45,00\end{array}$ & & \\
\hline \multirow{2}{*}{ Burger King } & \multirow{2}{*}{2} & \multirow{2}{*}{$\begin{array}{l}\text { San Isidro y } \\
\text { Miraflores }\end{array}$} & \multirow{2}{*}{2} & $\begin{array}{l}\text { Lunes a jueves: } 15,00 \\
\text { a } 20,00 \text {. }\end{array}$ & \multirow{2}{*}{3,50} & \multirow{2}{*}{30 minutos } \\
\hline & & & & $\begin{array}{l}\text {.Sábado y domingo: } \\
30,00 \text { a } 45,00\end{array}$ & & \\
\hline \multirow{2}{*}{ KFC } & \multirow{2}{*}{9} & $\begin{array}{l}\text { San Borja, La } \\
\text { Molina, San } \\
\text { Isidro. }\end{array}$ & \multirow{2}{*}{2} & $\begin{array}{l}\text { Lunes a jueves: } 15,00 \\
\text { a } 20,00 \text {. }\end{array}$ & \multirow{2}{*}{3,50} & \multirow{2}{*}{30 minutos } \\
\hline & & $\begin{array}{l}\text { San Miguel, } \\
\text { Miraflores y } \\
\text { Surco }\end{array}$ & & $\begin{array}{l}\text { Sábado y domingo: } \\
30,00 \text { a } 45,00\end{array}$ & & \\
\hline \multirow[b]{2}{*}{ Pizza Hut } & \multirow[b]{2}{*}{9} & \multirow{2}{*}{$\begin{array}{l}\text { San Borja, La } \\
\text { Molina, San } \\
\text { Isidro, } \\
\text { San Miguel, } \\
\text { Miraflores y } \\
\text { Surco }\end{array}$} & \multirow[b]{2}{*}{2} & $\begin{array}{l}\text { Lunes a jueves: } 12,00 \\
\text { a } 20,00 \text {. }\end{array}$ & \multirow[b]{2}{*}{3,50} & \multirow[b]{2}{*}{30 minutos } \\
\hline & & & & $\begin{array}{l}\text { Sábado y domingo: } \\
35,00 \text { a } 45,00\end{array}$ & & \\
\hline \multirow[t]{2}{*}{ Pasta Pronta } & \multirow[t]{2}{*}{2} & \multirow{2}{*}{$\begin{array}{l}\text { Surco y San } \\
\text { Miguel }\end{array}$} & \multirow[t]{2}{*}{2} & Pedido mínimo: 20,00. & \multirow[t]{2}{*}{0,00} & \multirow{2}{*}{40 minutos } \\
\hline & & & & .De 45,00 a 60,00 . & & \\
\hline $\begin{array}{l}\text { Mediterraneo } \\
\text { Chicken }\end{array}$ & 5 & $\begin{array}{l}\text { San Isidro, } \\
\text { Sanborja, Jesus } \\
\text { Maria, } \\
\text { Miraflores y } \\
\text { Surco. }\end{array}$ & 2 & . De: 35,00 & 3,0 & 30 minutos \\
\hline
\end{tabular}

Elaboración propia

De la Tabla 1.13 se desprende que:

- KFC lideraba en el número de locales que ofrecían el servicio de delivery en la competencia, e igualaban con Bembos en este número.

- Bembos y KFC ofrecían el servicio de delivery en los mismos distritos, por lo que podríamos decir que KFC era competencia directa de Bembos en este servicio.

- El tiempo máximo que ofrecían las cadenas de la competencia, directa como indirecta, era de 30 minutos máximos para la entrega a domicilio. 
- Surco, Miraflores y San Miguel eran los distritos con presencia importante del servicio de delivery de comida rápida.

De la Tabla 1.13 se puede resaltar una de las estrategias de servicio que utilizaban con mayor énfasis las empresas de comida rápida, en el momento de la investigación, era el factor de tiempo total de atención del pedido por delivery, usando como parámetro máximo de tiempo total: 30 minutos. Este caló con mucha fuerza en los consumidores influyendo muchas veces en su elección.

Incluso varias de ellas indicaban en su publicidad que si la entrega se excedía de los 30 minutos el pedido era gratis, tal como se muestran en la Figura 1.9.

Figura 1.9

Ejemplo campaña: 30 minutos o gratis

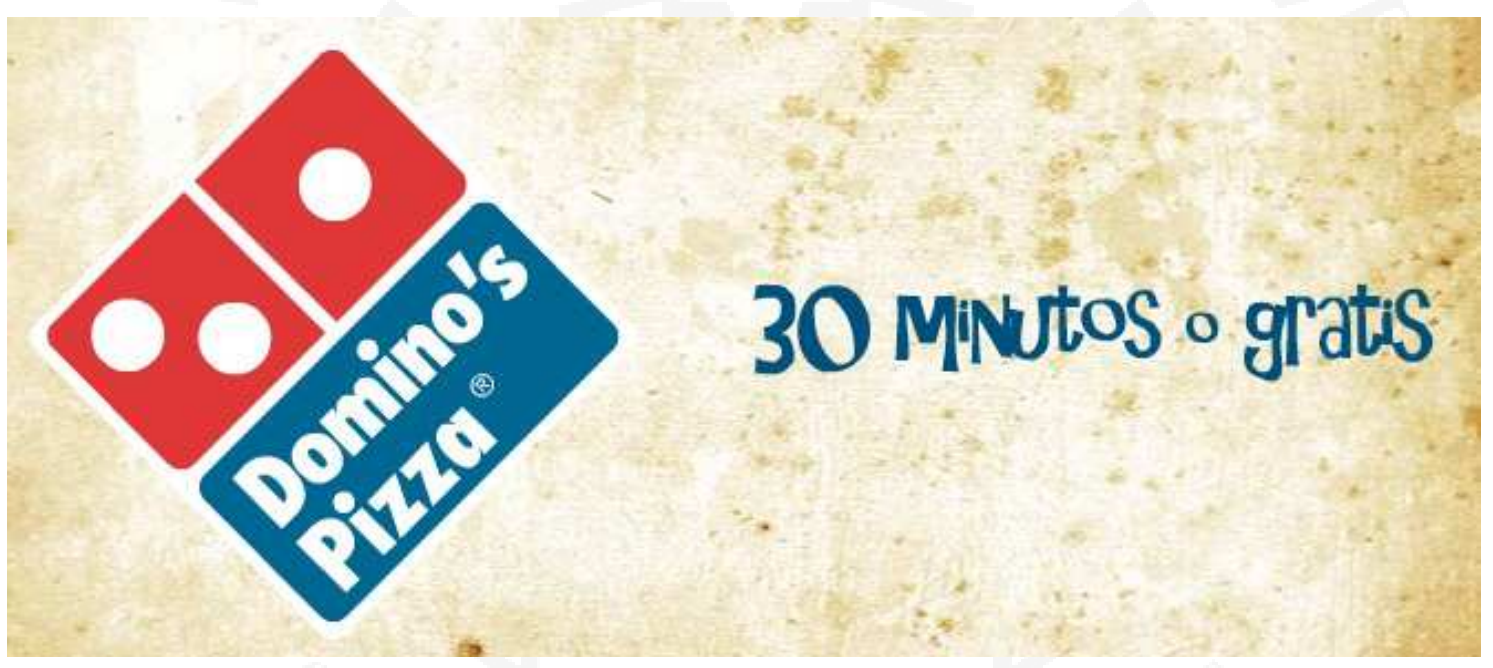

Fuente: Imágenes Google (2017)

Basado en ello es que Bembos se trazó como parámetro que la atención de su línea de delivery debía tener el tiempo máximo de 30 minutos.

\subsection{Descripción del problema.}

Para la detección del nivel de satisfacción en la línea de servicio delivery, y su impacto en los objetivos de la empresa se utilizó el:

- El nivel de reclamos.

- El número de comandas. 
El diagnóstico que se realizó para definir los problemas de la línea de producción y comercialización del delivery, se basó en la información histórica generada en el periodo de enero a abril del mismo año en que se desarrolló el estudio.

De ambos indicadores se construyó además un indicador consolidado, en forma de ratio, denominado: índice de insatisfacción.

\subsubsection{El nivel de reclamos}

La cadena Bembos instaló el mecanismo de Buzón de Sugerencias como canal de medición de la satisfacción de los clientes, a través del cual se recibían sus comentarios, reclamos, críticas y recomendaciones, de forma anónima e impersonal, usando para ello el llenado de un formato que se colocaba en un buzón instalado en cada local.

Luego, cada semana, la responsable de Servicio al Cliente (área encargada de administrar este esquema) recogía los formatos de cada buzón y realizaba un análisis mensual de los mismos, identificando y clasificándolos en: reclamos (también críticas) y sugerencias (comentarios y recomendaciones).

La responsable de servicio al cliente preparaba un reporte mensual con los resultados de los buzones, y presentaba dicho análisis al comité de dirección y gestión.

Luego dicho comité, con la participación adicional de los responsables intermedios de cada tema, operaban como el círculo de calidad, el cual estaba encargado de buscar las soluciones a los problemas.

Dentro de los reclamos también se realizaba una clasificación, agrupándolos en reclamos de: producto, local, precio, personal y otros. En el formato también se pedía especificar el lugar de la atención a la cual se hace referencia el reclamo. En la Tabla 1.14 se muestran la clasificación de los reclamos y su alcance. 
Tabla 1.14

Clasificación de reclamos del buzón de sugerencias, 1997

\begin{tabular}{|l|l|}
\hline Reclamo sobre: & \multicolumn{1}{c|}{ Alcance } \\
\hline Producto & $\begin{array}{l}\text { Sobre los productos en general: } \\
\text { calidad, empaque y otros. }\end{array}$ \\
\hline Local & $\begin{array}{l}\text { Sobre infraestructura, diseño, } \\
\text { limpieza y otros del local. }\end{array}$ \\
\hline Precio & Sobre el precio, ofertas y otros. \\
\hline Personal & $\begin{array}{l}\text { Sobre la atención, vestimenta, } \\
\text { limpieza, entre otros. }\end{array}$ \\
\hline Tiempo & Básicamente demoras. \\
\hline
\end{tabular}

Elaboración propia

En la Tabla 1.15 se muestran el total de reclamos y sugerencias en el periodo de diagnóstico.

Tabla 1.15

Reclamos y sugerencias, enero-abril, 1997.

\begin{tabular}{|l|c|c|c|c|c|c|c|c|c|c|c|c|}
\hline & \multicolumn{3}{|c|}{ ENERO } & \multicolumn{3}{|c|}{ FEBRERO } & \multicolumn{3}{c|}{ MARZO } & \multicolumn{3}{c|}{ ABRIL } \\
\hline TEMAS & Reclamos & Sugerencias & Total & Reclamos & Sugerencias & Total & Reclamos & Sugerencias & Total & Reclamos & Sugerencias & Total \\
\hline Producto & 702 & 47 & 749 & 737 & 65 & 802 & 779 & 68 & 847 & 840 & 83 & 923 \\
\hline Local & 56 & 55 & 111 & 67 & 29 & 96 & 29 & 54 & 83 & 9 & 82 & 91 \\
\hline Precio & 33 & 1 & 34 & 22 & 2 & 24 & 16 & 17 & 33 & 10 & 4 & 14 \\
\hline Personal & 49 & 26 & 75 & 19 & 3 & 22 & 31 & 9 & 40 & 31 & 3 & 34 \\
\hline Tiempo & 152 & 4 & 156 & 167 & 11 & 178 & 186 & 5 & 191 & 189 & 16 & 205 \\
\hline Total & $\mathbf{9 9 2}$ & $\mathbf{1 3 3}$ & $\mathbf{1 1 2 5}$ & $\mathbf{1 0 1 2}$ & $\mathbf{1 1 0}$ & $\mathbf{1 1 2 2}$ & $\mathbf{1 0 4 1}$ & $\mathbf{1 5 3}$ & $\mathbf{1 ~ 1 9 4}$ & $\mathbf{1 0 7 9}$ & $\mathbf{1 8 8}$ & $\mathbf{1 2 6 7}$ \\
\hline
\end{tabular}

Fuente: Bembos S.A.C., (1997)

Elaboración propia

En la Figura 1.10 y Tabla 1.16 se muestra el resultado del análisis de la Curva de Pareto de los reclamos, en el periodo enero a abril (1997), en la que se aprecia que los reclamos de producto y tiempo alcanzan el $91 \%$ de la frecuencia de los reclamos. 
Figura 1.10

Gráfica de Pareto: división por tipo de reclamos en buzón de sugerencias, enero-abril, 1997

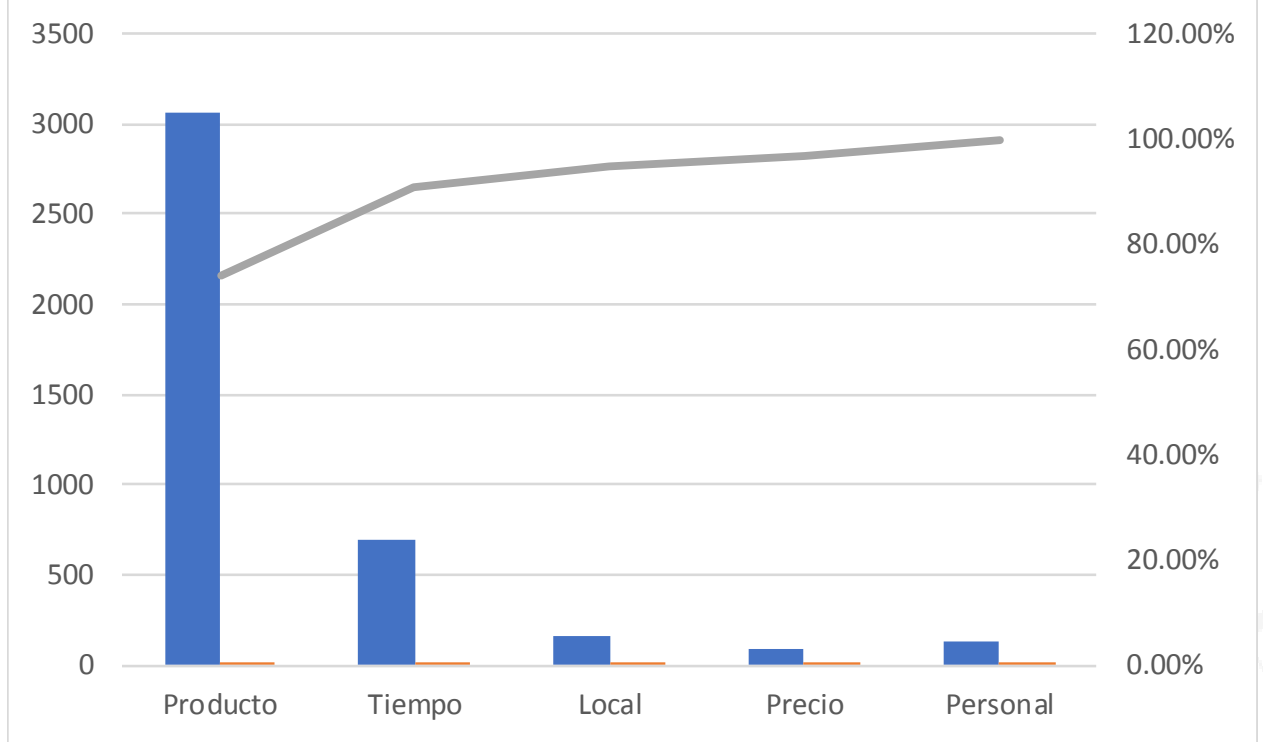

Fuente: Bembos S.A.C., (1997)

Elaboración propia

Tabla 1.16

División por tipo de reclamos en buzón de sugerencias, enero-abril, 1997

\begin{tabular}{|l|c|c|c|}
\hline \multicolumn{4}{|c|}{ DIS TRIBUCIÓN DE RECLAMOS EN EL BUZÓN DES UGERENCIAS } \\
\hline \multicolumn{4}{|c|}{ Periodo de Enero - Abril 1997 } \\
\hline \multicolumn{1}{|c|}{ PRODUCTO } & Frecuencia & $(\%)$ & Porcentaje acumulado \\
\hline Producto & 3058 & $74 \%$ & $74 \%$ \\
\hline Tiempo & 694 & $17 \%$ & $91 \%$ \\
\hline Local & 161 & $4 \%$ & $95 \%$ \\
\hline Precio & 81 & $2 \%$ & $97 \%$ \\
\hline Personal & 130 & $3 \%$ & $100 \%$ \\
\hline Total & $\mathbf{4 1 2 4}$ & $\mathbf{1 0 0 \%}$ & \\
\hline
\end{tabular}

Fuente: Bembos S.A.C., (1997)

Elaboración propia

Además, en la Figura 1.11 se puede apreciar que la tendencia era creciente mes a mes durante el periodo de diagnóstico. 
Figura 1.11

Curva de comportamiento mes del total de reclamos, enero-abril, 1997

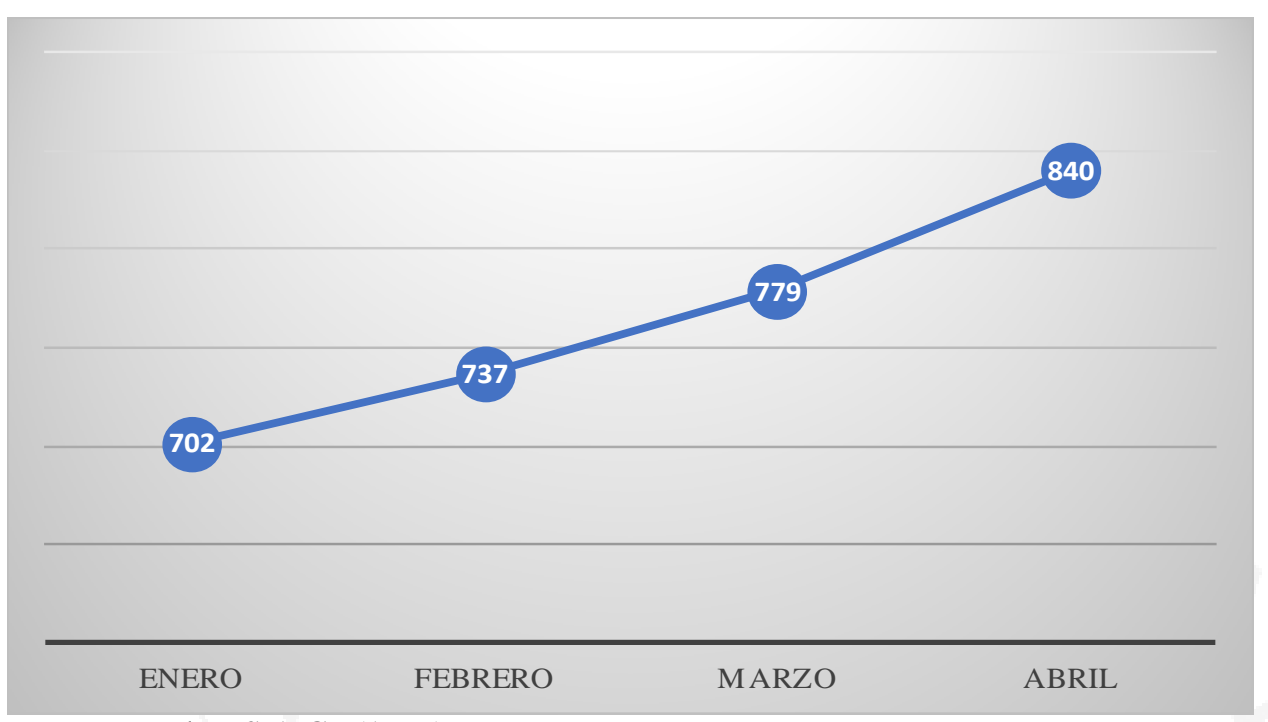

Fuente: Bembos S.A.C., (1997)

Elaboración propia

Como se puede ver en la tabla 1.17 y figura 1.12, el mayor número de reclamos, en todos los meses del periodo analizado se encuentra en la línea de servicio de delivery, alcanzando en total 2270 (74\%) versus los 788 (26\%) asociados a los locales.

Tabla 1.17

Reclamos de producto por línea de atención, enero-abril, 1997.

\begin{tabular}{|l|c|c|c|c|c|c|}
\hline & ENERO & FEBRERO & MARZO & ABRIL & TOTAL & \\
\hline CANAL & & & & & & $\%$ \\
\hline Delivery & 471 & 536 & 590 & 673 & $\mathbf{2 2 7 0}$ & $\mathbf{7 4 \%}$ \\
\hline Local & 231 & 201 & 189 & 167 & $\mathbf{7 8 8}$ & $\mathbf{2 6 \%}$ \\
\hline Total & $\mathbf{7 0 2}$ & $\mathbf{7 3 7}$ & $\mathbf{7 7 9}$ & $\mathbf{8 4 0}$ & $\mathbf{3 0 5 8}$ & $\mathbf{1 0 0 \%}$ \\
\hline
\end{tabular}

Fuente: Bembos S.A.C. (1997)

Elaboración propia 
Figura 1.12

Distribución de los reclamos por la línea de atención, enero-abril, 1997.

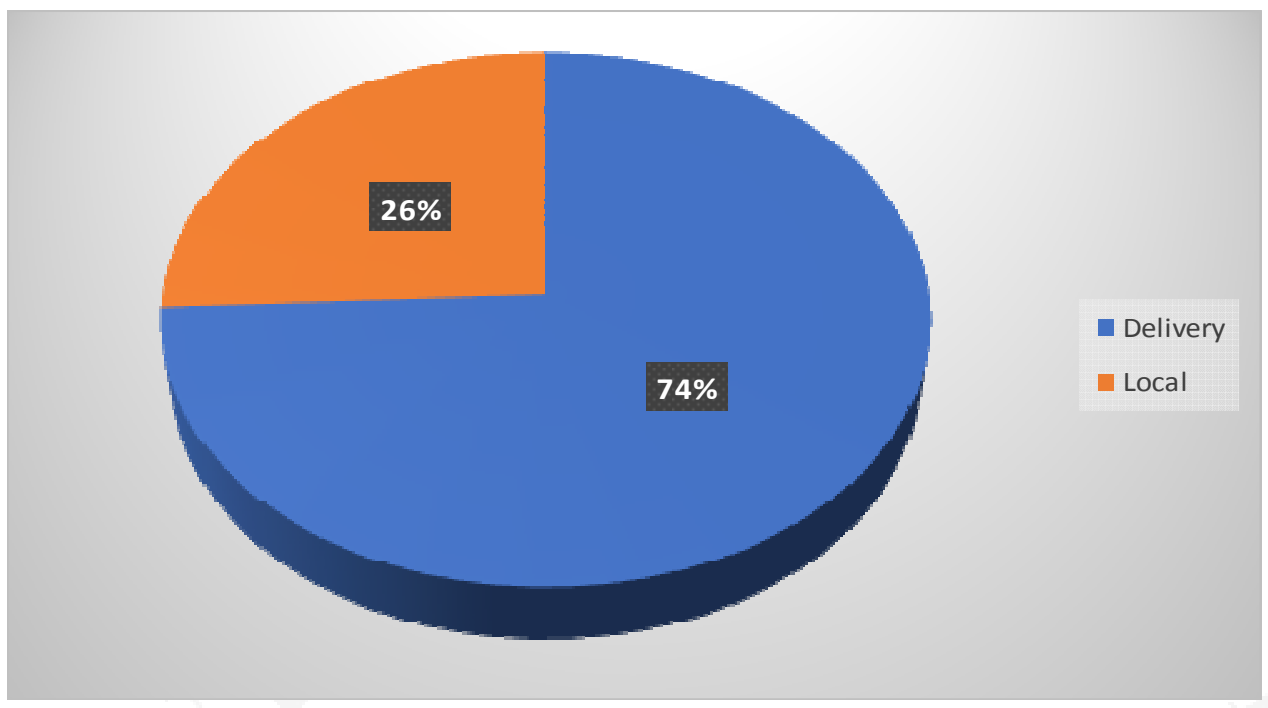

Elaboración propia.

Y también seguía una tendencia creciente como lo muestra la Figura 1.13

Figura 1.13

Curva de comportamiento mes de los reclamos del delivery, enero-abril,1997

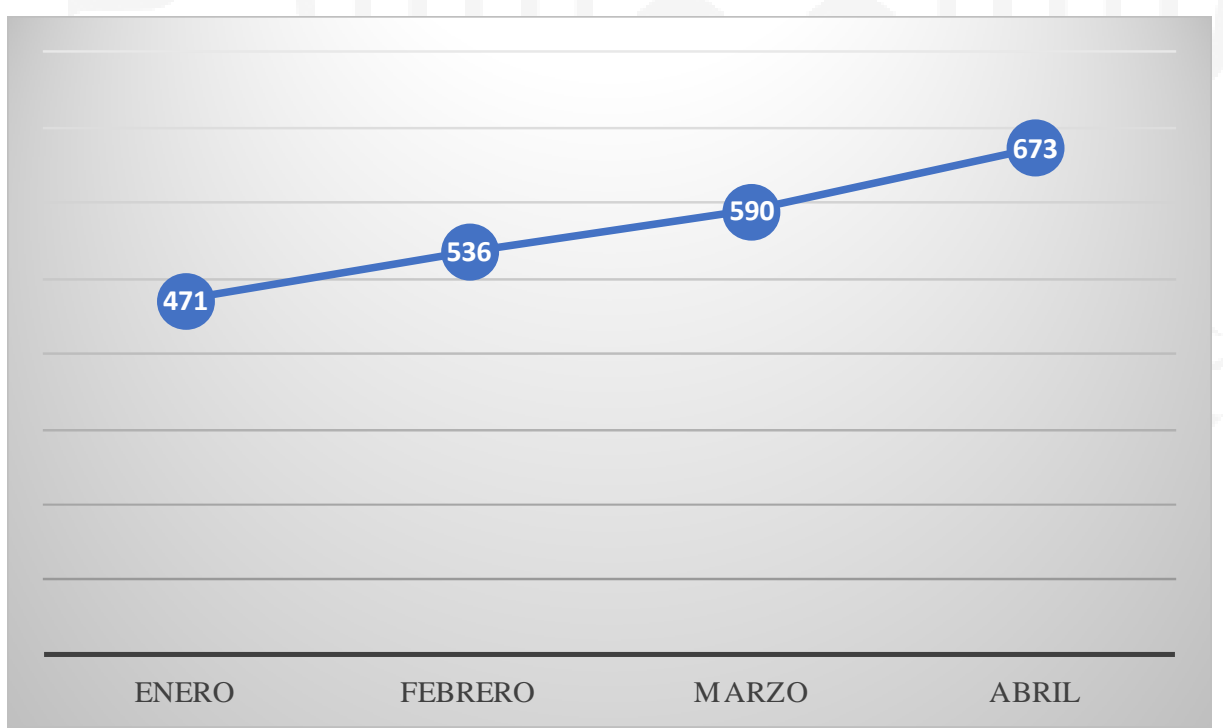

Fuente: Bembos S.A.C., (1997)

Elaboración propia

Es así como el comité de dirección y gestión decide que se realice el estudio de mejora sobre el producto dentro de la línea de producción y comercialización del delivery. 


\subsubsection{Reclamos del producto en la línea delivery}

Del análisis de los reclamos del producto, dentro de la línea de delivery, la Tabla 1.18 presenta el número de reclamos que se presentaron por tipo de producto en el periodo de diagnóstico, de cual se aprecia que la mayoría de los reclamos de producto estaban concentrados en el producto: hamburguesa, con el $72 \%$, seguido de papas fritas con el $28 \%$, por lo que se decidió dirigir el estudio primero en minimizar los reclamos de la hamburguesa.

Tabla 1.18

División de los reclamos por tipo de producto, enero-abril, 1997.

\begin{tabular}{|l|c|c|c|c|c|c|}
\hline & ENERO & FEBRERO & MARZO & ABRIL & TOTAL & \\
\hline PRODUCTO & & & & & & $\%$ \\
\hline Hamburguesa & 274 & 350 & 455 & 545 & $\mathbf{1 6 2 5}$ & $\mathbf{7 2 \%}$ \\
\hline Papas Fritas & 193 & 181 & 131 & 124 & $\mathbf{6 2 9}$ & $\mathbf{2 8 \%}$ \\
\hline Otros & 4 & 5 & 4 & 3 & $\mathbf{1 6}$ & $\mathbf{1 \%}$ \\
\hline Total & $\mathbf{4 7 1}$ & $\mathbf{5 3 6}$ & $\mathbf{5 9 0}$ & $\mathbf{6 7 3}$ & $\mathbf{2 2 7 0}$ & $\mathbf{1 0 0 \%}$ \\
\hline
\end{tabular}

Fuente: Bembos S.A.C., (1997)

Elaboración propia

En la Tabla 1.19 se muestran los reclamos de producto por tipo de problema encontrado en el periodo de diagnóstico.

Tabla 1.19

Reclamos de producto por tipo de problema, enero-abril, 1997.

\begin{tabular}{|l|c|c|c|c|c|c|}
\hline & ENERO & FEBRERO & MARZO & ABRIL & TOTAL & \\
\hline $\begin{array}{c}\text { TIPO DE } \\
\text { PROBLEMA }\end{array}$ & & & & & & \\
\hline Frio & 228 & 299 & 396 & 497 & $\mathbf{1 4 2 0}$ & $\mathbf{8 7 \%}$ \\
\hline Desarmado & 39 & 48 & 52 & 41 & $\mathbf{1 8 0}$ & $\mathbf{1 1 \%}$ \\
\hline Pan mojado & 6 & 2 & 4 & 4 & $\mathbf{1 7}$ & $\mathbf{1 \%}$ \\
\hline Carne cruda & 1 & 1 & 2 & 4 & $\mathbf{9}$ & $\mathbf{1 \%}$ \\
\hline Total & $\mathbf{2 7 4}$ & $\mathbf{3 5 0}$ & $\mathbf{4 5 5}$ & $\mathbf{5 4 6}$ & $\mathbf{1 6 2 5}$ & $\mathbf{1 0 0 \%}$ \\
\hline
\end{tabular}

Fuente: Bembos S.A.C., (1997)

Elaboración propia

De esta Tabla 1.19 se puede apreciar que el problema de frío es el que ha liderado todos los meses los reclamos del producto hamburguesa. 
En la Figura 1.14 se muestra la Curva de Pareto de la división de los tipos de problemas de los reclamos en el producto hamburguesa en el periodo de diagnóstico, en el que se puede apreciar que entre los problemas: frío y desarmado, se presentaba el $98,44 \%$ de los problemas.

\section{Figura 1.14}

Curva de Pareto: división de los problemas de los reclamos del producto hamburguesa, enero-abril, 1997.

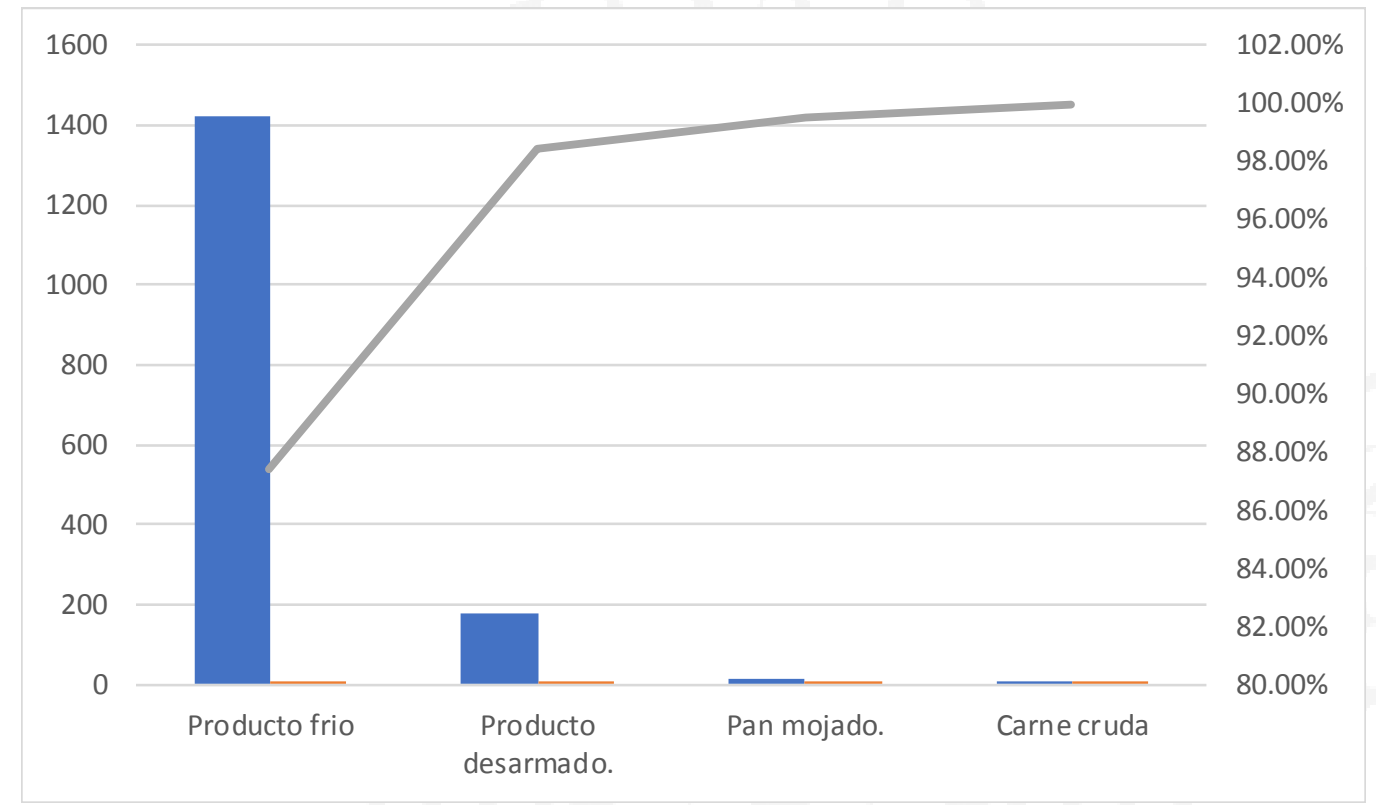

Fuente: Bembos S.A.C., (1997)

Elaboración propia

\subsubsection{Número de comandas}

Se le denomina comanda al pedido o solicitud por cada llamada al Delivery. Esta medición del número de comandas, en un periodo de tiempo, nos permite conocer el comportamiento y la tendencia de la demanda por el servicio en dicho periodo.

Se eligió periodo de medición: mes, y se elaboraban cuadros de control de seguimiento del comportamiento de los pedidos por local.

Es importante tomar en cuenta que los pedidos tienen un comportamiento cíclico en el año, ello porque existen meses con mayor demanda producto de fechas festivas: Día de la madre, día del padre, feriados largos, entre otros; y de las campañas organizadas por el área de marketing de la empresa; sin embargo, este indicador nos permite: 
- Conocer en qué meses, de bajos pedidos, se debían colocarse campañas.

- Comparar el comportamiento de los meses en diferentes años y de esta forma poder determinar que la tendencia de la demanda por el servicio.

- Realizar las proyecciones y presupuestos necesarios en:

- Los presupuestos financieros de ingresos y rentabilidad.

- El programa de compras locales e importación de los principales insumos.

- Los presupuestos de marketing.

- Comparar entre los mismos locales de la cadena y con la competencia.

Este índice se mide por local y por el total de la cadena.

\section{Figura 1.15}

Comandas por mes del total de la línea de delivery, enero-abril, 1997

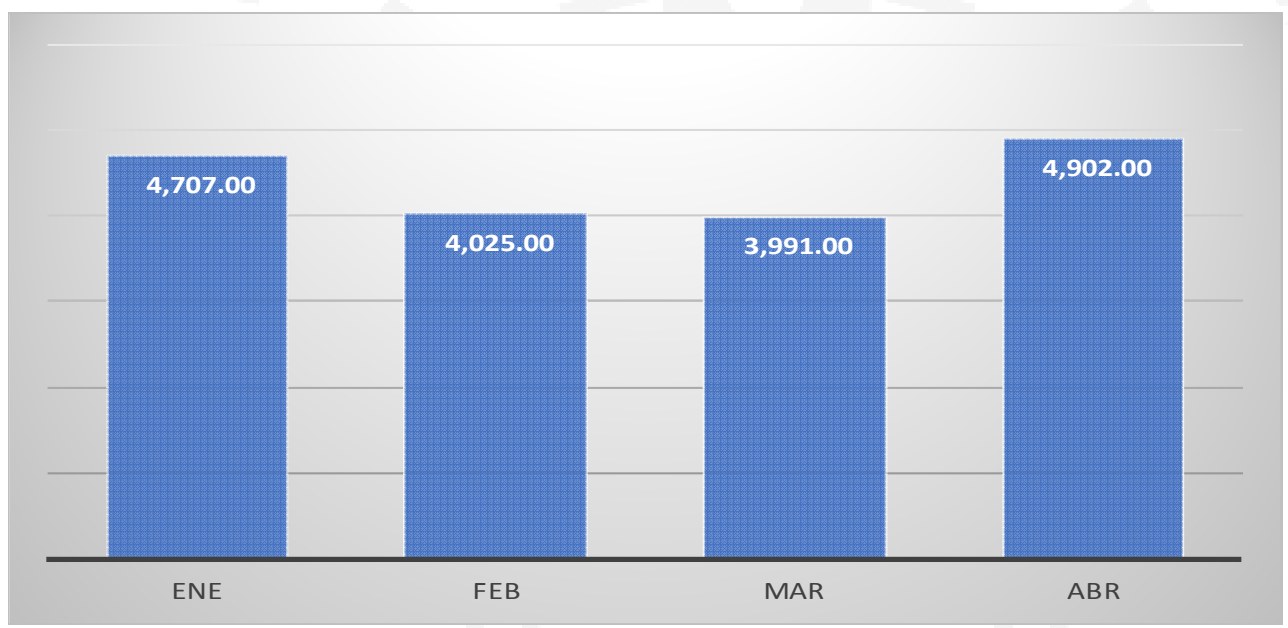

Fuente: Bembos S.A.C., (1997)

Elaboración propia

En la Figura 1.15 se aprecia lo siguiente:

- Las comandas totales de enero a abril fueron de un total de 17,625, siendo el pico más bajo el de febrero.

- Los meses de febrero y marzo sufrieron un descenso con respecto a enero.

- En el mes de abril hubo una ligera recuperación debido a la aplicación de algunas de las medidas de mejora, producto del análisis durante la realización del estudio, y que se tomaron a partir de la segunda quincena de abril.

Es así que se puede apreciar que las comandas, es decir el número de pedidos, también mostraban un descenso en el periodo de diagnóstico. 


\subsection{3 Índice de insatisfacción.}

De ambos indicadores se creó un indicador, en forma de ratio, al que denominamos: índice de insatisfacción, cuya fórmula se presenta a continuación:

\section{Índice de insatisfacción $=$ Número de reclamos/ Número de comandas}

En la Tabla 1.20 se muestran los resultados del cálculo del índice de insatisfacción en el periodo del diagnóstico.

Tabla 1.20

ndice de insatisfacción de la línea de delivery de Bembos, enero-abril, 1997

\begin{tabular}{|l|c|c|c|c|c|}
\hline \multicolumn{7}{|c|}{ ÍNDICE DE INSATISFACCIÓN DEL DELIVERY } \\
\hline & ENERO & FEBRERO & MARZO & ABRIL & TOTAL \\
\hline Reclamos & 471 & 536 & 590 & 673 & 2270 \\
\hline Comandas & 4707 & 4025 & 3991 & 4902 & 17625 \\
\hline $\begin{array}{l}\text { Índice de } \\
\text { Insatisfacción }\end{array}$ & $\mathbf{1 0 . 0 1 \%}$ & $\mathbf{1 3 . 3 2 \%}$ & $\mathbf{1 4 . 7 8 \%}$ & $\mathbf{1 3 . 7 3 \%}$ & $\mathbf{1 2 . 8 8 \%}$ \\
\hline
\end{tabular}

Fuente: Bembos S.A.C. (1997)

Elaboración propia

De dicha tabla se puede notar que el índice de insatisfacción promedio es de 12,88\%.

En la Figura 1.16 se aprecia el comportamiento que sigue el índice de insatisfacción en el periodo de diagnóstico, enero a abril 1997. Es importante mencionar que en la segunda quincena del mes de abril se adelantaron algunas mejoras dentro del avance, que se presentaba al comité de dirección y gestión, de los resultados preliminares del estudio de mejora. 
Figura 1.16

Comportamiento mes del índice de insatisfacción, enero-abril, 1997.

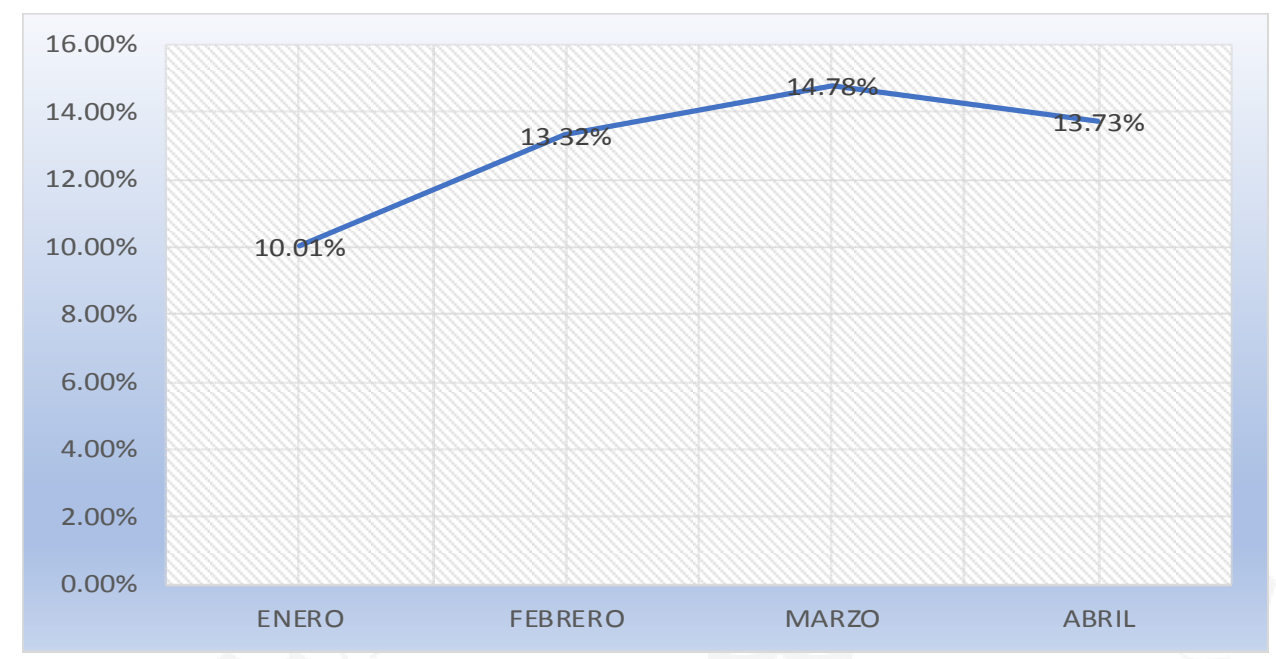

Elaboración propia.

\subsection{Análisis FORD}

Con el propósito de detectar, sobre la línea de servicio de delivery, cuáles eran las ventajas comparativas frente a la competencia, cuales los problemas y falencias, cuales los riesgos del mercado o entorno y cuales las oportunidades que brindaba el mercado en ese momento, se utilizó la metodología del análisis de las fortalezas, debilidades, oportunidades y riesgos, conocida como la Matriz FORD.

En la Tabla 1.21 se presenta el resultado del análisis de la matriz FORD. 
Tabla 1.21

Matriz FORD de Bembos, 1997

\begin{tabular}{|c|c|}
\hline Oportunidades & Fortalezas \\
\hline $\begin{array}{l}\text { Distritos con alta densidad poblacional que no estaban } \\
\text { siendo totalmente atendidos por la oferta actual. }\end{array}$ & $\begin{array}{l}\text { Un producto diferenciado perteneciente a una cadena en } \\
\text { ese momento líder del mercado. }\end{array}$ \\
\hline $\begin{array}{l}\text { Incremento del tamaño de mercado originado por las } \\
\text { ventajas que ofrece un servicio a domicilio. }\end{array}$ & La mayor cobertura al tener mas locales que la competencia. \\
\hline $\begin{array}{l}\text { Crecimiento en la demanda de este servicio impulsada por } \\
\text { el incremento en la difusión de eventos transmitidos por } \\
\text { las televisoras locales: fútbol, voley, El Oscar, entre otros. }\end{array}$ & $\begin{array}{l}\text { Los años de experiencia en brindar este servicio de delivery, } \\
\text { pero que en ese periodo se vió amenazado por la fuerte } \\
\text { competencia. }\end{array}$ \\
\hline $\begin{array}{l}\text { Incremento de la demanda originado por la situación de } \\
\text { inseguridad que se vivía producto del terrorismo en la } \\
\text { ciudad. }\end{array}$ & $\begin{array}{l}\text { La capacidad de poder ofrecer en forma rápida distintas } \\
\text { ofertas y promociones en combinaciones con los productos } \\
\text { hacían que los clientes se inclinen por elegir a bembos } \\
\text { (Decisiones de innovación en Perú). }\end{array}$ \\
\hline $\begin{array}{l}\text { El tiempo muy reducido para almorzar que tenían y tienen } \\
\text { las personas en sus trabajos. }\end{array}$ & $\begin{array}{l}\text { La marca peruana generaba una afectividad mayor que las } \\
\text { otras marcas extranjeras; ademas de tener el posicionamiento } \\
\text { de: "sabor nacional". }\end{array}$ \\
\hline Riesgos & Debilidades \\
\hline $\begin{array}{l}\text { Problemas políticos y económicos que influían en las } \\
\text { expectativas racionales de la población en cuanto a su } \\
\text { bienestar futuro y por ende en el consumo. }\end{array}$ & Realización en forma manual de gran parte del proceso. \\
\hline $\begin{array}{l}\text { Fuerte competencia en el sector de Comida Rápida en } \\
\text { general. }\end{array}$ & $\begin{array}{l}\text { No contar con la cantidad suficiente de motos y autos para } \\
\text { la entrega. }\end{array}$ \\
\hline $\begin{array}{l}\text { El ingreso al mercado peruano del gigante de Comida } \\
\text { Rápida: McDonald’s líder mundial en esta actividad: } \\
\text { expectativa, precios bajos, entre otros. }\end{array}$ & $\begin{array}{l}\text { El producto Bembos es de difícil armado y manipuleo por las } \\
\text { caraterísticas propias de sus insumos. por lo que no llegaba } \\
\text { siempre en las mejores condiciones. }\end{array}$ \\
\hline $\begin{array}{l}\text { Las cadenas extranjeras tenían mayor espalda financiera } \\
\text { por lo que aplicaban campañas de precios muy bajos. }\end{array}$ & Poca experiencia en la línea de servicio delivery. \\
\hline
\end{tabular}

Elaboración propia 


\section{CAPÍTULO II: OBJETIVOS DE LA INVESTIGACIÓN}

\subsection{Objetivo general.}

Realizar un estudio de mejora para reducir el nivel de insatisfacción y mejorar las ventas en la línea de producción y comercialización del servicio de delivery de Bembos S.A.C.

\subsection{Objetivos específicos.}

- Reducir el número de reclamos de la línea delivery.

- Incrementar la demanda del servicio, medido a través del número de comandas (pedidos) de este servicio.

- Disminuir el tiempo total de atención colocándolo dentro el rango del mercado: 30 minutos 


\section{CAPÍTULO III: ALCANCE Y LIMITACIONES DE LA INVESTIGACIÓN}

\subsection{Alcance.}

Los alcances de la investigación fueron los siguientes:

- El estudio se desarrolló sobre la línea de servicio de delivery, que viene a ser el segundo canal de venta de la cadena Bembos. La primera es a través de sus locales. Esta línea pasa por las áreas de: central de pedidos, producción y despacho. Las áreas de: recepción de pedidos y despacho pertenecen a la gestión de comercialización del producto.

- En la Tabla 3.1 se muestran las funciones generales que se desarrollan en las áreas antes indicadas.

Tabla 3.1.

Áreas y funciones en la línea de delivery de Bembos, 1997.

\begin{tabular}{|c|c|}
\hline Áreas & Función \\
\hline \multirow[t]{2}{*}{ Central de pedidos } & $\begin{array}{l}\text { Recibír las llamadas telefónicas de los clientes. El } \\
\text { télefono era el único medio de comunicación posible } \\
\text { con la empresa. Aun no se habían desarrollado los } \\
\text { otros medios virtuales como la web, redes sociales, } \\
\text { entre otros. }\end{array}$ \\
\hline & Coordinar con el local destinado a la atención. \\
\hline \multirow{2}{*}{ Producción } & Fabricar el producto de acuerdo al pedido. \\
\hline & Empacar el pedido para su entrega al cliente. \\
\hline Despacho & $\begin{array}{l}\text { Realizar la elección del medio de transporte y } \\
\text { coordinar el despacho del pedido. }\end{array}$ \\
\hline
\end{tabular}

Elaboración propia

- El estudio se realizó tomando como periodo de diagnóstico, para la detección de los problemas y búsqueda de soluciones, los cuatro primeros meses del año en que se desarrolló la investigación: enero a abril de 1997.

- Para la primera evaluación de los resultados, producto de las mejoras aplicadas del estudio, se tomaron los resultados de los meses de mayo a diciembre del mismo año. 
- Se consideró la información global de toda la línea de delivery, es decir la suma de todos los 9 locales que ofrecían el servicio, de los 13 que tenía la cadena en el momento del estudio. Los locales, y sus ubicaciones, se presentaron en el capítulo en la Tabla 1.1.

\subsection{Limitaciones}

Las limitaciones encontradas en la investigación fueron las siguientes:

- Gran parte del registro de la información era manual por el bajo desarrollo tecnológico de la época y porque además la cadena no contaba con un sistema moderno incluso para la época.

- En el caso del estudio de la competencia, se tuvieron algunas dificultades para obtener la información de su línea de delivery, teniendo que apoyarnos en la observación y datos dados por los clientes o personal de dichas cadenas.

- El plazo para el desarrollo del estudio y la aplicación de las mejoras tenía que ser corto, ello por dos factores: el incremento en los reclamos de los clientes y la fuerte competencia que se inició en el sector con el reciente ingreso de la cadena McDonald's.

- No se disponía ni de grandes recursos ni de mucho tiempo para las mejoras, por lo que había que buscar soluciones creativas, de aplicación rápida, y de inversión mínima.

- El desarrollo tecnológico de la época en lo que respecta a las comunicaciones como el registro o transferencia de información era bastante incipiente. No se contaban con las tecnologías actuales así, por ejemplo, las transferencias de los pedidos a cada local, tomados por la central de pedidos de delivery, se realizaban por fax, y se confirmaban por radio. 


\section{CAPÍTULO IV: JUSTIFICACIÓN DE LA INVESTIGACIÓN}

\subsection{Justificación técnica}

Técnicamente era viable puesto que existían soluciones tecnológicas en materiales, procesos y otros que ya estaban siendo utilizados en el mercado por las cadenas extranjeras, y que con el apoyo de las herramientas y metodologías que nos ofrece la ingeniería industrial, era posible realizar con éxito la investigación.

\subsection{Justificación económica.}

Económicamente fue viable porque de no realizarse las mejoras encontradas en la investigación los ingresos por la línea de delivery hubiesen seguido en descenso perjudicando las finanzas de la empresa, además del impacto negativo en la calidad del producto y su posicionamiento. Existían soluciones, como las aplicadas, que no exigieron grandes recursos de inversión, costo o gasto, y algunas de ellas incluso fueron realizadas sin desembolsar dinero alguno por tratarse de un reforzamiento en la capacitación del personal.

\subsection{Justificación social}

La comida rápida es una de las alternativas para aquellas personas que no cuentan con el tiempo para preparar sus alimentos y necesitan alimentarse durante el día. A pesar de la fuerte satanización de esta línea de alimentos, no podemos poner en el mismo saco a todas las empresas de comida rápida. Existen empresas como Bembos que tiene una fuerte responsabilidad social y que bajo ese esquema desarrollan y ofrecen productos con los más altos estándares de calidad en sus insumos como en su preparación. Además, es una alternativa a precios módicos para muchos. La extensión del servicio a través del delivery brinda además una solución para el cliente al evitarle que tenga que trasladarse reduciendo el tiempo en su periodo de refrigerio y el costo del transporte. 


\section{CAPÍTULO V: PROPUESTAS Y RESULTADOS}

\subsection{Identificación de las causas raíces del problema.}

Habiéndose detectado que existía un nivel de insatisfacción creciente en el servicio que brinda la cadena en su línea de delivery, y que este nivel de insatisfacción, que llegó a su nivel más alto en el mes de marzo (14,78\%), estaba principalmente evidenciado en dos problemas principales: producto frío y exceso en el tiempo total de la atención; ambos como resultado del análisis de los reclamos en los puntos anteriores; se procedió a utilizar la técnica del diagrama causa-efecto para explicar las razones de los dos problemas y con ello, la del grado de insatisfacción.

Se realizó técnica de la lluvia de ideas desde las categorías presentes en el servicio:

- Método.

- Materiales

- Ambiente.

- Control.

- Personal.

- Sistemas y equipos.

En la figura 5.1 se muestra el diagrama causa-efecto para explicar las razones del grado de insatisfacción. 
Figura 5.1

Diagrama causa-efecto, 1997

\section{DIAGRAMA CAUSA - EFECTO}

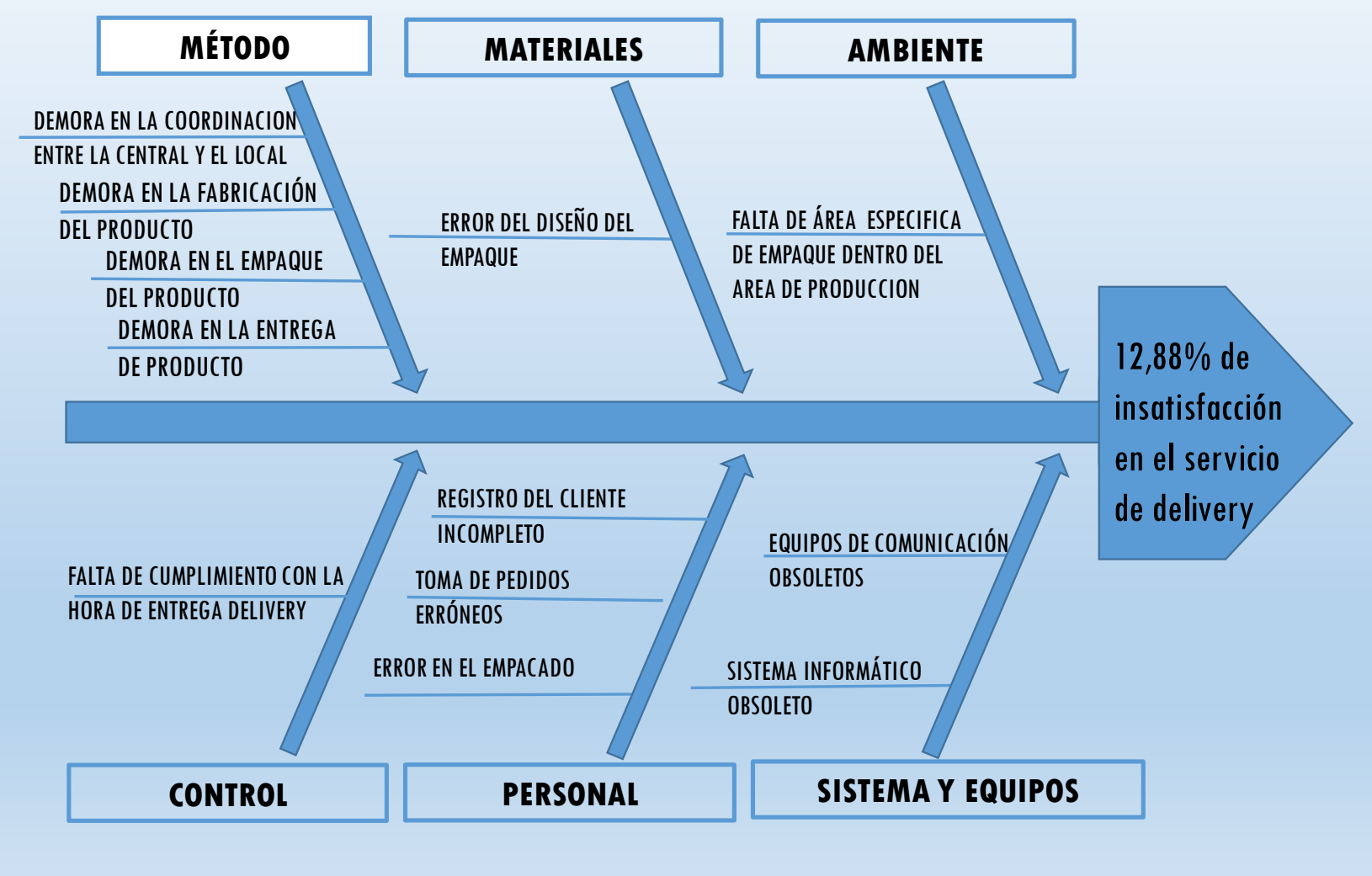

Elaboración propia 


\subsection{Soluciones propuestas para los problemas encontrados.}

Utilizando una vez más la técnica de la lluvia de ideas, se presentaron al comité de dirección y gestión, varias soluciones para cada una de las causas detectadas en el diagrama causan-efecto, Figura 1.16, eligiéndose las óptimas bajo el método de ponderación realizado por el comité de dirección y gestión.

A continuación, se presentan las soluciones propuestas elegidas para cada causa o grupos de causas.

\subsubsection{Método}

En la Figura 5.1 se puede apreciar que las subcausas encontradas para la causa: método, con la técnica de lluvia de ideas, fueron un grupo de demoras en varias partes de la línea de delivery. Estas son:

- Demora en la coordinación entre la Central de Pedidos y el local.

- Demora en la fabricación del producto.

- Demora en el empaque del producto.

- Demora en la entrega del producto,

Para confirmar estas subcausas se realizaron dos pruebas de medición de los tiempos.

Se utilizó la técnica de muestreo, eligiendo muestras de 8 semanas en periodos de dos meses, y de cada semana: dos días, el miércoles y el domingo, realizando una medición en cada uno de los turnos.

Esta elección se basó en que, según los registros de ventas históricos, en los fines de semana la demanda del servicio era mayor y diferente a los días normales de la semana. Asimismo, el turno B tenía un comportamiento de demanda diferente al del turno A según se explicó anteriormente. De esta forma se abarcaría todo el universo de la demanda.

En la Tabla 5.1 se muestra la fórmula que se utilizó para la medición del total del tiempo en la atención de un pedido en la línea de delivery. 


\section{Tabla 5.1}

Fórmula de cálculo del tiempo total de atención en delivery, 1997

\begin{tabular}{|c|l|}
\hline \multicolumn{2}{|c|}{ Tiempo total = T(Central) $+\mathbf{T}($ Local $)+\mathbf{T}($ Transporte $)$} \\
\hline T(Central) & Tiempo transcurrido en la central hasta el envío de la comanda. \\
\hline T(Producción) & $\begin{array}{l}\text { Tiempo transcurrido desde la recepción de la comanda hasta tener el } \\
\text { pedido empacado para su envio. }\end{array}$ \\
\hline Transporte $)$ & Tiempo transcurrido por el transporte al domicilio \\
\hline
\end{tabular}

Elaboración propia.

Las zonas de atención que le correspondían a cada local, denominadas burbuja de atención, que se muestran en el Anexo 1, fueron determinadas de acuerdo con el criterio aproximado de distancia en el mapa, excepto en el caso del local de La Molina donde se utilizó una moto para determinar hasta qué punto se podían atender pedidos en un máximo de tiempo.

El mapa ubicado en la central de Rapid Bembos contaba con una delimitación de las zonas a las que no llegaba el servicio.

Las burbujas de atención que cada local atendía se muestran en el anexo 1. Son copias simples de los planos de cobertura originales, que en aquel entonces eran tomados de la guía de calles que venían con la guía telefónica.

Los resultados promedio se muestran en la Tabla 5.2, y como se puede apreciar todos los locales, salvo el local La Molina, superaban el valor de 30 minutos, máximo valor aceptado por la cadena. 
Tabla 5.2

Resultados muestreo: tiempo total de atención delivery, abril 1997.

\begin{tabular}{|l|r|r|r|r|r|r|r|r|}
\hline & \multicolumn{2}{|c|}{ T(Central) } & \multicolumn{1}{c|}{ T(Producción) } & \multicolumn{1}{c|}{ T(Transporte) } & \multicolumn{2}{c|}{ TOTAL } \\
\hline \multicolumn{1}{|c|}{ TURNO } & A & \multicolumn{1}{c|}{ B } & \multicolumn{1}{c|}{ A } & \multicolumn{1}{c|}{ B } & \multicolumn{1}{c|}{ A } & \multicolumn{1}{c|}{ B } & A & B \\
\hline LOCAL & & & & & & & & \\
\hline Benavides & 1,5 & 1,5 & 8,5 & 10,0 & 27,0 & 28,0 & $\mathbf{3 7 , 0}$ & $\mathbf{3 9 , 5}$ \\
\hline Dasso & 4,0 & 5,0 & 9,0 & 8,0 & 24,0 & 26,0 & $\mathbf{3 7 , 0}$ & $\mathbf{3 9 , 0}$ \\
\hline Monterrico & 4,0 & 4,0 & 12,0 & 21,0 & 15,0 & 10,0 & $\mathbf{3 1 , 0}$ & $\mathbf{3 5 , 0}$ \\
\hline Aurora & 3,0 & 2,0 & 13,0 & 15,0 & 20,0 & 21,0 & $\mathbf{3 6 , 0}$ & $\mathbf{3 8 , 0}$ \\
\hline San Miguel & 3,0 & 6,0 & 18,0 & 6,0 & 16,0 & 24,0 & $\mathbf{3 7 , 0}$ & $\mathbf{3 6 , 0}$ \\
\hline San Borja & 2,0 & 4,5 & 7,0 & 10,0 & 21,0 & 25,0 & $\mathbf{3 0 , 0}$ & $\mathbf{3 9 , 5}$ \\
\hline Texaco (Aramburu) & 8,0 & 3,0 & 10,0 & 17,0 & 15,0 & 18,0 & $\mathbf{3 3 , 0}$ & $\mathbf{3 8 , 0}$ \\
\hline La Molina & 4,0 & 4,0 & 12,0 & 8,0 & 14,0 & 17,0 & $\mathbf{3 0 , 0}$ & $\mathbf{2 9 , 0}$ \\
\hline Gardenias & 3,0 & 7,0 & 8,0 & 9,0 & 23,0 & 18,0 & $\mathbf{3 4 , 0}$ & $\mathbf{3 4 , 0}$ \\
\hline
\end{tabular}

Fuente: Bembos S.A.C., (1997)

Además, se aprecia una dispersión muy alta en los tiempos de las áreas de: central de pedidos y producción, en los diferentes locales de la cadena, lo cual demuestra una falta de estandarización en ellas. En el caso del área de producción había locales que colocaban los pedidos de delivery al final de la cola de pedidos generados en el local, sin respetar el hecho de que debían seguir una cola paralela.

Como se analizó en el acápite 1.2.1, análisis de la competencia, se mostró que el tiempo máximo que ofrecía las otras cadenas era de 30 minutos, es por ello que Bembos decide colocarse como ese parámetro máximo de tiempo, y porque, además, en los reclamos recibidos a través del buzón de sugerencias, el problema tiempo era uno de los más frecuentes, demostrado en el análisis de los reclamos en el acápite 1.3.1.

Las soluciones elegidas para esta causa se muestran en la tabla 5.3. 
Tabla 5.3

Soluciones para la causa: método, 1997.

\begin{tabular}{|c|c|c|c|}
\hline \multirow{2}{*}{$\begin{array}{l}\text { Demora en la } \\
\text { coordinación } \\
\text { entre la central y } \\
\text { el local. }\end{array}$} & $\begin{array}{l}\text { Solución: } \\
\text { Adquirir una línea telefónica } \\
\text { directa entre la central y cada } \\
\text { local. }\end{array}$ & \multirow{2}{*}{$\begin{array}{l}\text { Demora en la } \\
\text { fabricación del } \\
\text { producto }\end{array}$} & $\begin{array}{l}\text { Solución: } \\
\text { Adquirir un horno eléctrico de } \\
\text { almacenamiento de carnes cocidas, } \\
\text { que mantenga los niveles de } \\
\text { hidratación y temperatura. }\end{array}$ \\
\hline & $\begin{array}{l}\text { Beneficio: } \\
\text { Transferencia de datos en línea } \\
\text { entre la central de pedidos y los } \\
\text { locales. }\end{array}$ & & $\begin{array}{l}\text { Beneficio: } \\
\text { Reducción en el tiempo de } \\
\text { producción. }\end{array}$ \\
\hline \multirow{2}{*}{$\begin{array}{l}\text { Demora en el } \\
\text { empaque del } \\
\text { producto }\end{array}$} & \begin{tabular}{|l|} 
Solución: \\
Reforzamiento de capacitación al \\
personal encargado del \\
empaque.
\end{tabular} & \multirow{2}{*}{$\begin{array}{l}\text { Demora en la } \\
\text { entrega del } \\
\text { producto }\end{array}$} & 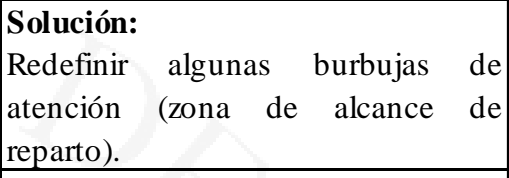 \\
\hline & $\begin{array}{l}\text { Beneficio: } \\
\text { Reducción de los tiempos de } \\
\text { empaque. }\end{array}$ & & $\begin{array}{l}\text { Beneficio: } \\
\text { Reducción del tiempo total de } \\
\text { máximo dentro de } 30 \text { minutos en } \\
\text { todos los locales. }\end{array}$ \\
\hline
\end{tabular}

Elaboración propia

A continuación, en la tabla 5.4, se muestran las inversiones, costos y gastos para cada una de las soluciones que se aplicaron para la causa: método.

Tabla 5.4

Inversiones, costos y gastos en las soluciones de la causa: método, 1997

\begin{tabular}{|c|c|c|c|}
\hline \multirow{2}{*}{$\begin{array}{l}\text { Demora en la } \\
\text { coordinación } \\
\text { entre la central y } \\
\text { el local. }\end{array}$} & \begin{tabular}{|l} 
Solución: \\
Adquirir una línea telefónica \\
directa entre la central y cada \\
local.
\end{tabular} & \multirow[t]{2}{*}{$\begin{array}{l}\text { Demora en la } \\
\text { fabricación del } \\
\text { producto }\end{array}$} & $\begin{array}{l}\text { Solución: } \\
\text { Adquirir un horno eléctrico que } \\
\text { mantiene los niveles de hidratación y } \\
\text { temperatura de las carnes cocidas } \\
\text { por una a dos horas. } \\
\end{array}$ \\
\hline & $\begin{array}{l}\text { Gasto: } \\
\text { S/.150,00 por mes por local }\end{array}$ & & $\begin{array}{l}\text { Inversión: } \\
\text { USD2,700 por máquina, una para } \\
\text { cada local. }\end{array}$ \\
\hline \multirow[t]{2}{*}{$\begin{array}{l}\text { Demora en el } \\
\text { empaque del } \\
\text { producto }\end{array}$} & \begin{tabular}{|l|} 
Solución: \\
Reforzamiento de capacitación al \\
personal encargado del \\
empaque.
\end{tabular} & \multirow[t]{2}{*}{$\begin{array}{l}\text { Demora en la } \\
\text { entrega del } \\
\text { producto }\end{array}$} & $\begin{array}{l}\text { Solución: } \\
\text { Reducción de algunas burbujas de } \\
\text { atención (zona de alcance de } \\
\text { reparto). }\end{array}$ \\
\hline & Sin gas to adicional. & & Sin gasto adicional. \\
\hline
\end{tabular}

Elaboración propia.

En el caso de la solución planteada para: demora en la entrega del producto, en el Anexo 1 se muestra las nuevas burbujas de atención para cada local. Después fue reemplazado el local de Dasso por uno nuevo en Camino Real. 


\subsubsection{Materiales}

En el tema de la causa: Materiales, tal como se muestra en el diagrama causa-efecto, se encontró el problema de: error en el diseño del empaque. Este problema fue corroborado al momento de analizar los reclamos en el acápite 1.3.1, puesto que en los resultados se indicaba que el producto llegaba frío.

En la Tabla 5.5 se muestra la solución elegida para resolver esta causa que contribuía en la insatisfacción de los clientes. En el Anexo 2 están los prototipos.

\section{Tabla 5.5}

Soluciones para la causa: materiales, 1997

\begin{tabular}{|c|l|}
\hline \multirow{2}{*}{$\begin{array}{c}\text { Error en el } \\
\text { diseño del } \\
\text { empaque. }\end{array}$} & $\begin{array}{l}\text { Solución: } \\
\text { Cambiar el empaque a una envoltura de un sobre } \\
\text { plastificado puesto luego en una cajita de cartón, en } \\
\text { reemplazo de la bols a de papel. }\end{array}$ \\
\cline { 2 - 2 } & $\begin{array}{l}\text { Beneficio: } \\
\text { Mantención de la temperatura y del armado. }\end{array}$ \\
\hline
\end{tabular}

Elaboración propia

En la tabla 5.6 se muestra el costo nuevo a asumir por la aplicación de esta solución, y el nuevo margen bruto por unidad de producto hamburguesa.

\section{Tabla 5.6}

Nuevo costo de empaque para la solución de la causa: material, 1997

\begin{tabular}{|l|c|l|c|l|}
\hline & Actual(S/.) & & Propuesta(S/.) & \\
\hline Precio Venta & 10,00 & & 10,00 & \\
\hline $\begin{array}{l}\text { Costo sin } \\
\text { Empaque }\end{array}$ & 3,50 & & 3,50 & \\
\hline Costo Empaque & 0,25 & $\begin{array}{l}\text { Sobre de } \\
\text { papel con } \\
\text { logo. }\end{array}$ & 0,65 & $\begin{array}{l}\text { Caja de cartón y sobre } \\
\text { especial plas tificado, ambos } \\
\text { con logo. }\end{array}$ \\
\hline Margen Bruto & 6,25 & & 5,85 & \\
\hline
\end{tabular}

Elaboración propia 


\subsubsection{Ambiente}

En diagrama de causa-efecto, figura 5.1, para el caso de la causa: ambiente, se determinó como subcausa: la falta de un área específica de empaque dentro del área de producción.

La producción de los pedidos de delivery son realizados en el mismo ambiente de cocina que fabrican los productos para venta en el local, es así como, la producción de estos últimos terminaba con colocar el producto en su empaque de papel y luego ponerlo sobre una bandeja de plástico. Para que luego, los encargados de la entrega en tienda, llamados Counter, tomen las bandejas y las colocan sobre el mostrador para su entrega a los clientes que están esperando en el salón.

No existía un área específica de empaque, y los pedidos de delivery esperaban en la línea para ser empacados por los Counter, dándose prioridad a los pedidos dentro del local. En esa espera existe una demora que aparte de incrementar el tiempo total del servicio, ocasiona que el producto se enfríe.

En la Tabla 5.7 se muestra la solución propuesta elegida para esta causa.

\section{Tabla 5.7}

Solución para la causa: ambiente, 1997

\begin{tabular}{|c|c|}
\hline $\begin{array}{l}\text { Falta de área } \\
\text { específica de } \\
\text { empaque dentro }\end{array}$ & $\begin{array}{l}\text { Solución: } \\
\text { Designar un área específica para empaque en el área de } \\
\text { producción, en la mesa se entrega. }\end{array}$ \\
\hline $\begin{array}{l}\text { del área de } \\
\text { producción. }\end{array}$ & $\begin{array}{l}\text { Beneficio: } \\
\text { Minimizar el tiempo de espera del producto para su empaque. }\end{array}$ \\
\hline
\end{tabular}

Elaboración propia

Esta solución no implicó un egreso adicional, tan solo se distribuyó mejor las zonas de trabajo en la mesa de producción.

\subsubsection{Sistema y equipos}

En la causa: sistema y equipos se detectaron las siguientes subcausas:

- Equipos de comunicación obsoletos.

- Sistema informático obsoleto 
En la Tabla 5.8 se presenta la solución que se adoptó. Es importante mencionar que por un tema de recursos limitados y de tiempo se dejó la solución del sistema informático para más adelante. Entre los objetivos del siguiente año estaba el de adquirir un sistema informático nuevo para toda la organización, que incluía a la línea de delivery. El proyecto abarcaba todas las áreas y líneas de negocio de la organización, y cuyo propósito era tener la información en línea y un tablero de control de mando.

\section{Tabla 5.8}

Solución para la causa: sistemas y equipos, 1997

\begin{tabular}{|c|l|}
\hline \multirow{2}{*}{$\begin{array}{c}\text { Equipos de } \\
\text { comunicación } \\
\text { obsoletos }\end{array}$} & $\begin{array}{l}\text { Solución: } \\
\text { Adquirir un equipo de radio portatil nuevo para cada local. }\end{array}$ \\
\cline { 2 - 3 } & $\begin{array}{l}\text { Beneficio: } \\
\text { Mejor y mas rápida comunicación en la coordinación entre la central } \\
\text { de delivery y el des pacho. }\end{array}$ \\
\hline \multirow{2}{*}{$\begin{array}{c}\text { Sistema } \\
\text { informático } \\
\text { obsoleto }\end{array}$} & $\begin{array}{l}\text { Solución: } \\
\text { Adquirir un sistema Teledata para integrar de manera electrónica la } \\
\text { transferencia de datos, dentro del plan de mejora tecnológica de la } \\
\text { cadena. }\end{array}$ \\
\cline { 2 - 3 } & $\begin{array}{l}\text { Beneficios: } \\
\text { Pedido electrónico compartido con los locales, evitando las } \\
\text { comunicaciones telefónicas o envios de fax entre ellos. } \\
\text { Reducción del tiempo de coordinación y por lo tanto del tiempo total } \\
\text { de atención. } \\
\text { Control en línea de la situación del pedido. }\end{array}$ \\
\hline
\end{tabular}

Elaboración propia

En la Tabla 5.9 se presentan los egresos que se asumieron para la aplicación de las soluciones de la causa: sistemas y equipos.

Tabla 5.9

Inversión, costo y gastos en la solución de la causa: sistemas y equipos, 1997

\begin{tabular}{|c|l|}
\hline \multirow{2}{*}{$\begin{array}{c}\text { Equipos de } \\
\text { comunicación } \\
\text { obsoletos }\end{array}$} & $\begin{array}{l}\text { Solución: } \\
\text { Adquirir un equipo de radio portatil nuevo para cada local. }\end{array}$ \\
\cline { 2 - 3 } & $\begin{array}{l}\text { Inversión: } \\
\text {.USD 100 por equipo de radio. Uno por cada local, 9 en total. }\end{array}$ \\
\hline \multirow{2}{*}{$\begin{array}{c}\text { Sistema } \\
\text { informático } \\
\text { obsoleto }\end{array}$} & $\begin{array}{l}\text { Solución: } \\
\text { Adquirir un sistema Teledata para integrar de manera electrónica la } \\
\text { transferencia de datos entre la central de pedidos y los locales }\end{array}$ \\
\cline { 2 - 3 } & $\begin{array}{l}\text { Inversión: } \\
\text { USD4,200. Incluia software, instalacion y capacitacion. }\end{array}$ \\
\hline
\end{tabular}

Elaboración propia 


\subsubsection{Personal}

En la causa: personal se encontraron las siguientes subcausas, tal como se muestra en la Figura 5.1:

- Registro de cliente incompleto.

- Toma de pedido erróneo.

- Error en el empacado.

En la Tabla 5.10 se presentan las soluciones que se eligieron para esta causa.

Tabla 5.10

Soluciones para la causa: personal, 1997

\begin{tabular}{|c|c|}
\hline \multirow{2}{*}{$\begin{array}{l}\text { Registro de } \\
\text { cliente } \\
\text { incompleto }\end{array}$} & $\begin{array}{l}\text { Solución: } \\
\text { Reforzamiento en la capacitación del proceso de registro. }\end{array}$ \\
\hline & $\begin{array}{l}\text { Beneficio: } \\
\text { Reducción del error. }\end{array}$ \\
\hline \multirow{2}{*}{$\begin{array}{l}\text { Toma de pedidos } \\
\text { erróneos }\end{array}$} & $\begin{array}{l}\text { Solución: } \\
\text { Reforzamiento en la capacitación. }\end{array}$ \\
\hline & $\begin{array}{l}\text { Beneficio: } \\
\text { Reducción del error. }\end{array}$ \\
\hline \multirow{2}{*}{$\begin{array}{l}\text { Error en el } \\
\text { empacado }\end{array}$} & $\begin{array}{l}\text { Solución: } \\
\text { Reforzamiento en la capacitación del proceso de empacado. }\end{array}$ \\
\hline & $\begin{array}{l}\text { Beneficio: } \\
\text { Reducción del error. }\end{array}$ \\
\hline
\end{tabular}

Elaboración propia.

En la aplicación de estas soluciones no hubo costos o gastos adicionales toda vez que las capacitaciones fueron dadas por personal de la empresa.

\subsubsection{Control}

En el caso de la causa: control, se detectó que la subcausa era la falta de cumplimiento de la hora de entrega del delivery. La solución para este tema estaba dada por derivación de las soluciones de las otras causas que influían el tiempo total había un seguimiento.

Sin embargo, se generó e incorporó el registro de control de la hora de entrega, a cargo del registro manual de los motorizados para monitorear el tiempo total, tal como se indica en la Tabla 5.11. 
Tabla 5.11

Solución para la causa: control, 1997

\begin{tabular}{|c|l|}
\hline $\begin{array}{c}\text { Falta de } \\
\text { cumplimiento de } \\
\text { la hora de } \\
\text { entrega. }\end{array}$ & $\begin{array}{l}\text { Solución: } \\
\text {. Derivada de las mejoras de tiempo de las otras causas. } \\
\text {. Registro de hora para monitoreo de cumplimiento. }\end{array}$ \\
\cline { 2 - 2 } & $\begin{array}{l}\text { Beneficio: } \\
\text { Mejora del cumpliento. }\end{array}$ \\
\hline
\end{tabular}

Elaboración propia

En la aplicación de esta solución no hubo gastos adicionales al ser los mismos motorizados los que, aprovechando la verificación del pedido al momento de la entrega al cliente, colocaban, en la copia de la comanda, la hora de la entrega.

Es así como se determinaron un grupo de soluciones a todas las causas encontradas, y que estaban originando un importante nivel de insatisfacción de los clientes que demandaban el servicio de delivery de Bembos. Estas soluciones fueron las mejoras propuestas y aplicadas producto de la investigación.

\subsection{Implementación de las soluciones elegidas.}

Las soluciones, mejoras, descritas en el acápite 5.4 se aplicaron siguiendo para ello un cronograma que se muestra en la Figura 5.2, el cual fue aprobado por el comité de dirección y gestión.

La implementación se inició a mediados de abril de 1997 y el cronograma se muestra en la figura 5.2. 
Figura 5.2

Cronograma de implementación de mejoras, 1997

\begin{tabular}{|c|c|c|c|c|c|c|c|c|c|c|c|c|c|}
\hline CAUSA & SUBCAUSA & MEJORAS & 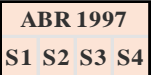 & \begin{tabular}{|c|c|} 
MAY 1997 \\
S1 S2 & S3 S S4 \\
\end{tabular} & \begin{tabular}{|c|c|} 
JUN 1997 \\
S1 S2 S3 S4
\end{tabular} & \begin{tabular}{|c|} 
JUL 1997 \\
S1 S2 S3 S4
\end{tabular} & \begin{tabular}{|c|} 
AGO 1997 \\
S1 S2 S3 S4
\end{tabular} & \begin{tabular}{r|r} 
SET 1997 \\
S1 S2 S3 S
\end{tabular} & \begin{tabular}{r|r} 
OCT 1997 \\
S1 S2 S3 S
\end{tabular} & \begin{tabular}{|r|r} 
NOV 1997 \\
S1 S2 S3 S
\end{tabular} & \begin{tabular}{|r} 
DIC 1997 \\
S1 S2 S3 S
\end{tabular} & & 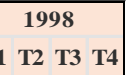 \\
\hline \multirow{4}{*}{ Método } & $\begin{array}{l}\text { Demora en la coordinación } \\
\text { entre la central y el local. }\end{array}$ & \begin{tabular}{|l|} 
Solución: \\
Adquirir una línea telefónica directa \\
entre la central y cada local.
\end{tabular} & & & & & & & & & & & \\
\hline & $\begin{array}{l}\text { Demora en la fabricación del } \\
\text { producto }\end{array}$ & \begin{tabular}{|l|} 
Solución: \\
Adquirir un Horno electrico de \\
almacenamiento de carnes cocidas, \\
que mantenga los niveles de \\
hidratacion y temperatura.
\end{tabular} & & & & & & & & & & & \\
\hline & $\begin{array}{l}\text { Demora en el empaque del } \\
\text { producto }\end{array}$ & \begin{tabular}{|l|} 
Solución: \\
Reforzamiento de capacitación al al \\
personal encargado del empaque.
\end{tabular} & & & & & & & & & & & \\
\hline & $\begin{array}{l}\text { Demora en la entrega del } \\
\text { producto }\end{array}$ & \begin{tabular}{|l|} 
Solución: \\
Se redefinir algunas burbujas de \\
atencion (zona de alcance de reparto).
\end{tabular} & & & & & & & & & & & \\
\hline Materiales & Frror en el diseño del empaque. & \begin{tabular}{|l|} 
Solución: \\
Cambiar el empaque a una envoltura \\
de un sobre plastificado puesto luego \\
en una cajita de carton, en reemplazo \\
de la bolsa de papel.
\end{tabular} & & & & & & & & & & & \\
\hline Ambiente & $\begin{array}{l}\text { Falta de área específica de } \\
\text { empaque dentro del área de } \\
\text { producción. }\end{array}$ & \begin{tabular}{|l|} 
Solución: \\
Designar un área específica para \\
empaque en el área de producción, en \\
la mesa se entrega.
\end{tabular} & & & & & & & & & & & \\
\hline \multirow{2}{*}{ Sistema y equipos } & $\begin{array}{l}\text { Equipos de comunicación } \\
\text { obsoletos }\end{array}$ & \begin{tabular}{|l|} 
Solución: \\
Adquirir una línea telefónica directa \\
entre la central y cada local.
\end{tabular} & & & & & & & & & & & \\
\hline & Sistema informático obs oleto & $\begin{array}{l}\text { Solución: } \\
\text { Adquirir un sistema Teledata. }\end{array}$ & & & & & & & & & & & \\
\hline \multirow{3}{*}{ Personal } & Registro de cliente incompleto & \begin{tabular}{|l|} 
Solución: \\
Reforzamiento en la capacitación del \\
proceso de registro.
\end{tabular} & & & & & & & & & & & \\
\hline & Toma de pedidos erroneos & $\begin{array}{l}\text { Solución: } \\
\text { Reforzamiento en la capacitación. }\end{array}$ & & & & & & & & & & & \\
\hline & Error en el empacado & \begin{tabular}{|l|} 
Solución: \\
Reforzamiento en la capacitación del \\
proceso de empacado.
\end{tabular} & & & & & & & & & & & \\
\hline Control & $\begin{array}{l}\begin{array}{l}\text { Falta de cumplimiento de la } \\
\text { hora de entrega. }\end{array} \\
\end{array}$ & $\begin{array}{l}\text { Solución: } \\
\text { Registro de hora para monitoreo de } \\
\text { cumplimiento. }\end{array}$ & & & & & & & & & & & \\
\hline
\end{tabular}

Elaboración propia. 


\subsection{Resultados de la implementación.}

Consecuentes con el objetivo principal y los específicos, presentados en el capítulo 2, se procedió, luego de la implementación de las mejoras, con las mediciones de los indicadores del acápite 1.3, con el propósito de verificar los resultados, los cuales se muestran a continuación.

Las mediciones se realizaron a partir del mes de mayo 1997.

\subsubsection{Nivel de reclamos}

En la figura 5.3 se muestran los resultados del número de reclamos por mes del producto hamburguesa en la línea de delivery, del año 1997. En ella se puede apreciar que, luego del inicio de la aplicación de las mejoras en la última semana de abril, según el cronograma de implementación indicado en la figura 5.2, a partir del mes de mayo el nivel de reclamos por mes muestra un importante descenso llegando a diciembre en un nivel mínimo de 66 reclamos.

\section{Figura 5.3}

Número de reclamos del producto hamburguesa en la línea delivery, enero-diciembre, 1997

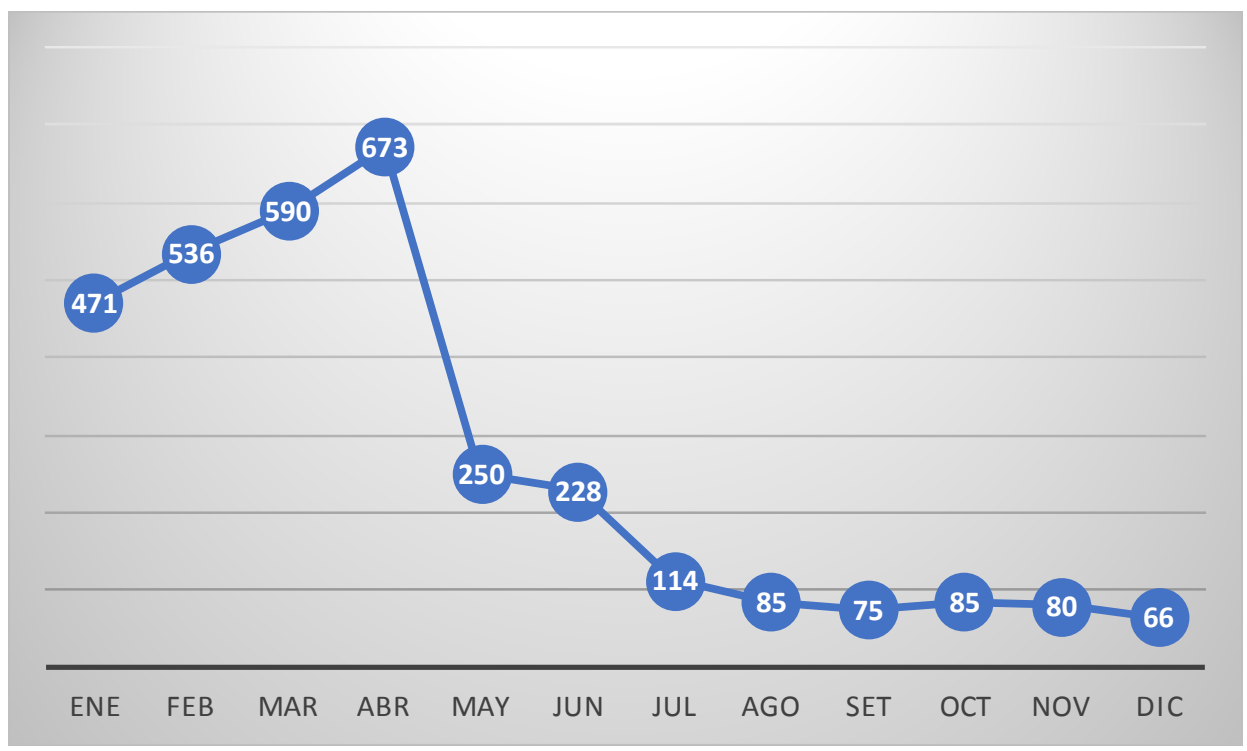

Fuente: Bembos S.A.C., (1997)

Elaboración propia 


\subsubsection{Número de comandas}

En la figura 5.4 se presentan los resultados del número de comandas, de la línea de delivery, en el año 1997.

Figura 5.4

Número de comandas en la línea de delivery, enero-diciembre, 1997

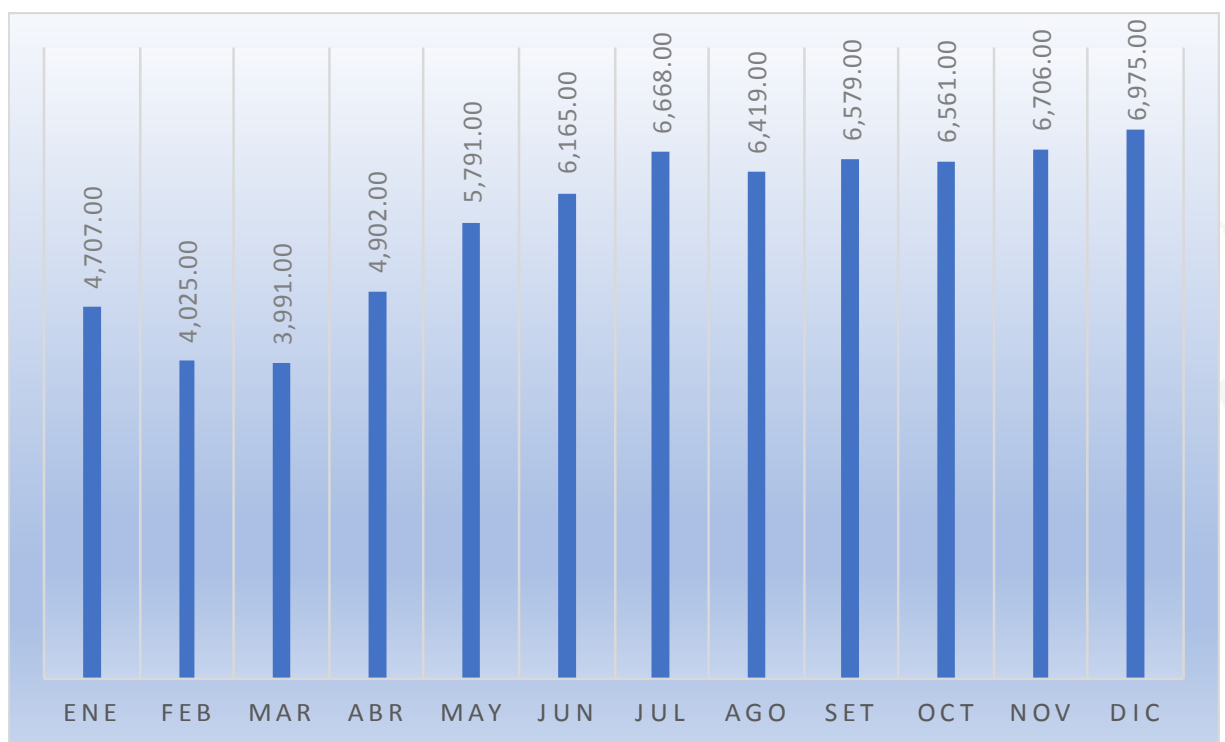

Fuente: Bembos S.A.C., (1997)

Elaboración propia

Se puede notar que el número de comandas mostro una tendencia creciente entre los meses de mayo a diciembre. Este resultado fue muy importante en términos de los resultados financieros con mayores ingresos para la cadena como en términos de consolidación de esta línea de servicio. Entre los meses de diciembre y abril hubo un crecimiento de aproximadamente el 40\%. Es importante también tomar en cuento los ciclos de ventas que se mencionaron en el acápite 1.1, en cuanto a que hay meses, cuyas ventas se ven influenciados por días festivos como mayo, julio y diciembre, como también por campañas específicas.

\subsection{3 Índice de insatisfacción}

Siguiendo el mismo esquema de medición de la insatisfacción descrito en el acápite 1.3.3, en la figura 5.5 se muestran los resultados del cálculo del índice de insatisfacción para todos los meses del año 1997. 


\section{Figura 5.5}

Índice de insatisfacción del producto en la línea de delivery, enero-diciembre, 1997

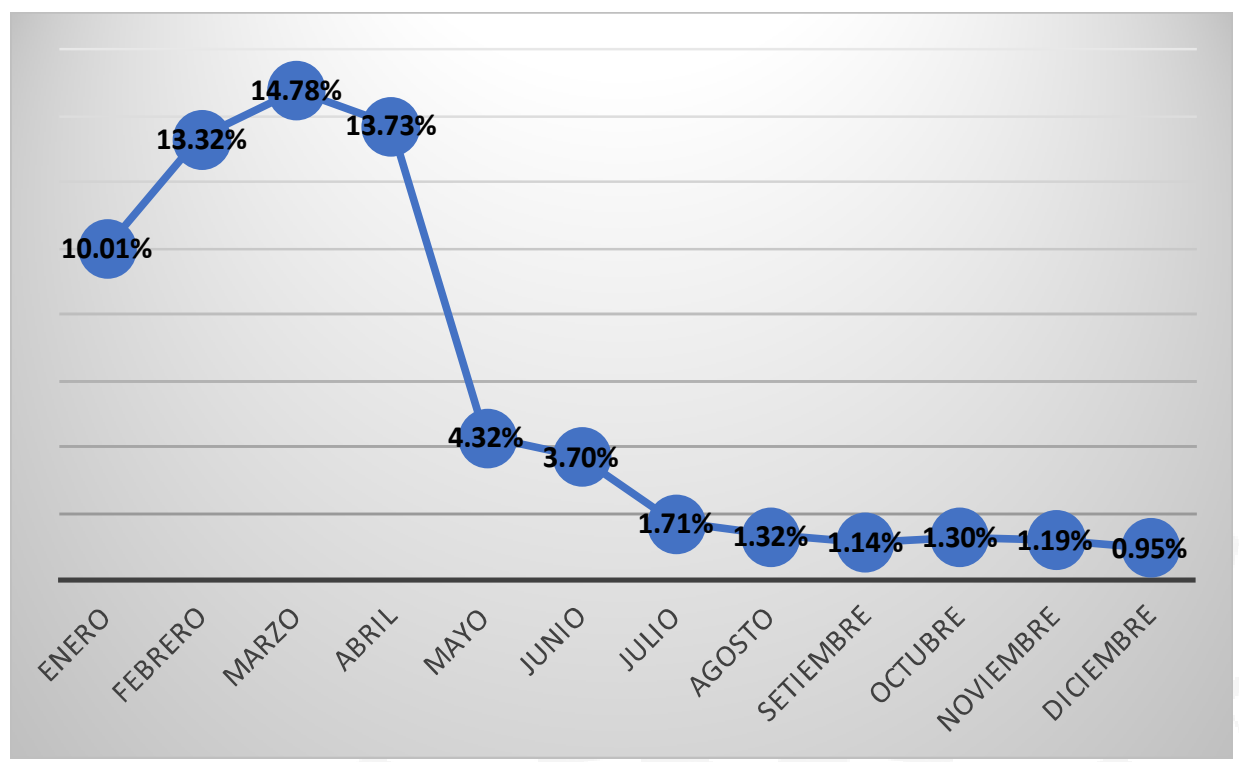

Fuente: Bembos S.A.C., (1997)

Elaboración propia

\subsubsection{Tiempo total de atención después de las mejoras.}

En la tabla 5.12 se muestra los resultados del promedio de los tiempos totales de atención por local en la línea de delivery, obtenidos en 4 muestreos realizados en el mes de mayo (2) y junio (2) del año de la investigación. 
Tabla 5.12

Resultado muestreo: tiempo total de atención del delivery por local, mayo-junio, 1997

\begin{tabular}{|l|r|r|r|r|r|r|r|r|r|}
\hline & \multicolumn{2}{|l|}{ T(Central) } & \multicolumn{2}{l|}{ T(Producción) } & \multicolumn{2}{l|}{ T(Transporte) } & \multicolumn{2}{l|}{ TOTAL } \\
\hline LOCAL & \multicolumn{1}{|l|}{ A } & B & A & B & A & B & A & \multicolumn{1}{l|}{ B } \\
\hline Benavides & 1,0 & 1,0 & 8,0 & 9,0 & 19,5 & 18,5 & $\mathbf{2 8 , 5}$ & $\mathbf{2 8 , 5}$ \\
\hline Dasso & 3,0 & 4,0 & 8,0 & 6,0 & 16,0 & 19,0 & $\mathbf{2 7 , 0}$ & $\mathbf{2 9 , 0}$ \\
\hline Monterrico & 4,0 & 4,0 & 10,0 & 14,0 & 16,0 & 11,0 & $\mathbf{3 0 , 0}$ & $\mathbf{2 9 , 0}$ \\
\hline Aurora & 3,0 & 2,0 & 9,0 & 13,0 & 13,0 & 15,0 & $\mathbf{2 5 , 0}$ & $\mathbf{3 0 , 0}$ \\
\hline San Miguel & 2,0 & 5,0 & 11,0 & 6,0 & 13,0 & 17,5 & $\mathbf{2 6 , 0}$ & $\mathbf{2 8 , 5}$ \\
\hline San Borja & 2,0 & 4,0 & 5,0 & 10,0 & 21,0 & 15,0 & $\mathbf{2 8 , 0}$ & $\mathbf{2 9 , 0}$ \\
\hline Texaco (Aramburu) & 7,0 & 2,0 & 9,0 & 14,0 & 11,0 & 13,0 & $\mathbf{2 7 , 0}$ & $\mathbf{2 9 , 0}$ \\
\hline La Molina & 5,0 & 5,0 & 8,5 & 7,0 & 15,0 & 18,0 & $\mathbf{2 8 , 5}$ & $\mathbf{3 0 , 0}$ \\
\hline Gardenias & 2,5 & 6,0 & 6,5 & 9,0 & 19,0 & 13,0 & $\mathbf{2 8 , 0}$ & $\mathbf{2 8 , 0}$ \\
\hline
\end{tabular}

Fuente: Bembos S.A.C., (1997)

Elaboración propia.

\subsubsection{Ventas de la línea de delivery después de las soluciones.}

Luego de la aplicación de las soluciones, descritas en el acápite anterior, los resultados en ventas por mes, durante el 1997, también mostraron como resultado un importante incremento tal como se muestra en la figura 5.6.

Figura 5.6

Ventas por mes en la línea de delivery de Bembos, enero-diciembre, 1997

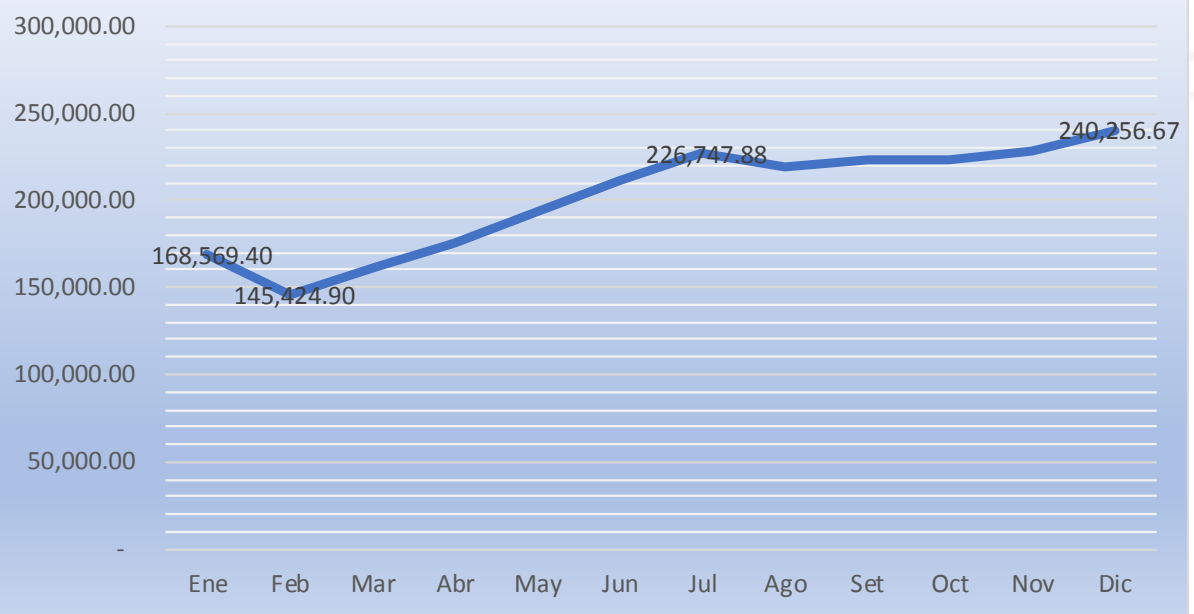

Fuente: Bembos S.A.C., (1997)

Elaboración propia 


\section{CONCLUSIONES}

- Se detectaron las causas que originaban un nivel alto de reclamos de los clientes en el servicio de delivery, enfocados principalmente dos aspectos o problemas: un producto hamburguesa que llegaba frío, y el no cumplimiento del tiempo total de atención de 30 minutos ofrecido; y con ello se plantearon y aplicaron las soluciones a dichas causas, las cuales eran: demoras en cada parte del proceso de atención, error en el diseño del empaque, falta de un área especial de empaque, errores en el personal de la central que toma el pedido como la que realiza el empaque, equipos y sistema obsoletos.

- Al aplicarse las soluciones se eliminaron los problemas de entrega de un producto hamburguesa frío y el no cumplimiento del tiempo total de atención, los cuales aparecían con mayor importancia en los registros de los reclamos, e impactaban negativamente en el nivel de insatisfacción, se redujo el índice a niveles mínimos, pasando de un promedio de $12,88 \%$ en los primeros cuatro meses, a menos del $1 \%$ en el último del año.

- Se incrementaron los niveles de ventas en un 37\% después de la aplicación de las mejoras, y con ello se logró una mayor contribución en los ingresos de la cadena por parte de esta línea de servicio.

- Se minimizaron los niveles de reclamos del producto hamburguesa en la línea delivery, alcanzando su nivel más bajo al cierre del año, 66, un 9,8\% del mes más alto del año, abril, que reportó 673 reclamos.

- El número de comandas (pedidos) al mes se incrementó pasando de 4902 en abril a 6975 en diciembre del mismo año, mostrando una clara tendencia creciente.

- Con las mejoras aplicadas los tiempos totales de atención se corrigieron lográndose alcanzar el máximo de 30 minutos en todos los locales de la cadena, colocando a Bembos al mismo nivel de competitividad de sus competidores en este aspecto. 


\section{RECOMENDACIONES}

- Durante la investigación se detectó que también se registraba, en los reclamos, asociados al servicio delivery, que el producto papas fritas no estaba llegando en las condiciones óptimas, por ello se recomendó realizar una investigación sobre las especificaciones y calidad del producto para esta línea de atención.

- Se detectó que había diferencias en la tecnología de los equipos de cocina entre los locales, es decir que había locales con equipos más modernos que les permitían una mayor velocidad de atención de los pedidos, por ello se recomendó una evaluación del tema.

- Se recomienda revisar el plan de capacitación del personal del área de producción, específicamente de los nuevos ingresantes, a fin de que logren un mejor y más pronto expertis de su función. 


\section{REFERENCIAS}

Amrop International y PAD Escuela de Dirección-Universidad de Piura. (2002). Compartiendo experiencias (Número 1). Piura: Caso Bembos Burger Grill.

Bembos S.A.C. (2019). ¿Cómo nació Bembos?. Recuperado de https://www.bembos.com.pe/nosotros/como-nacio-bembos

Google (2019). Imagen de la fachada de un local de Bembos. Recuperado de https://tujovialusil.files.wordpress.com/2011/03/fachada2b22bde2bbembos.jpeg

Google (2019). Imagen interior de la Planta central de fabricacion de Bembos. Recuperado de https://tikber.files.wordpress.com/2012/06/caso-bembos.pdf

Google (2019). Imagen de la hamburguesa clasica de Bembos. Recuperado de http://bembosperu.blogspot.com/2014/03/bembos-cuenta-con-una-clasificacionde.html

Google (2019). Imagen de ejemplo de un Combo de Bembos. Recuperado de https://www.bembos.com.pe/media/catalog/product/cache/1/image/9df78eab335 25d08d6e5fb8d27136e95/p/r/promo-10.png.png

Instituto Nacional de Estadística e Informática, INEI (1997). Boletín estadístico - marzo 1997. Lima 


\section{BIBLIOGRAFÍA}

Bedworth, D. D. y Bailey, J. E. (1998). Sistemas integrados de control de producción (1ra. ed.). Mexico: Editorial Limusa S.A. de C.V.

Bonilla, E., Diaz, B., Kleeberg, F. y Noriega, M. (2017). Mejora continua de los procesos: herramientas y técnicas (1ra. ed.). Lima: Universidad de Lima.: Fondo Editorial.

Monks, J. G. (1991). Administración de Operaciones (1ra. ed.). México: Mc Graw Hill.

Rozenberg B., A. (2000). Efectos de la crisis económica y financiera internacional, de 1997 a 1999, en la balanza de pagos del Perú. Recuperado de http://files.pucp.edu.pe/departamento/economia/DDD186.pdf. 


\title{
ANEXOS
}

\author{
ANEXO 1
}

Planos de los límites de atención del delivery por local de antes y después de la mejora

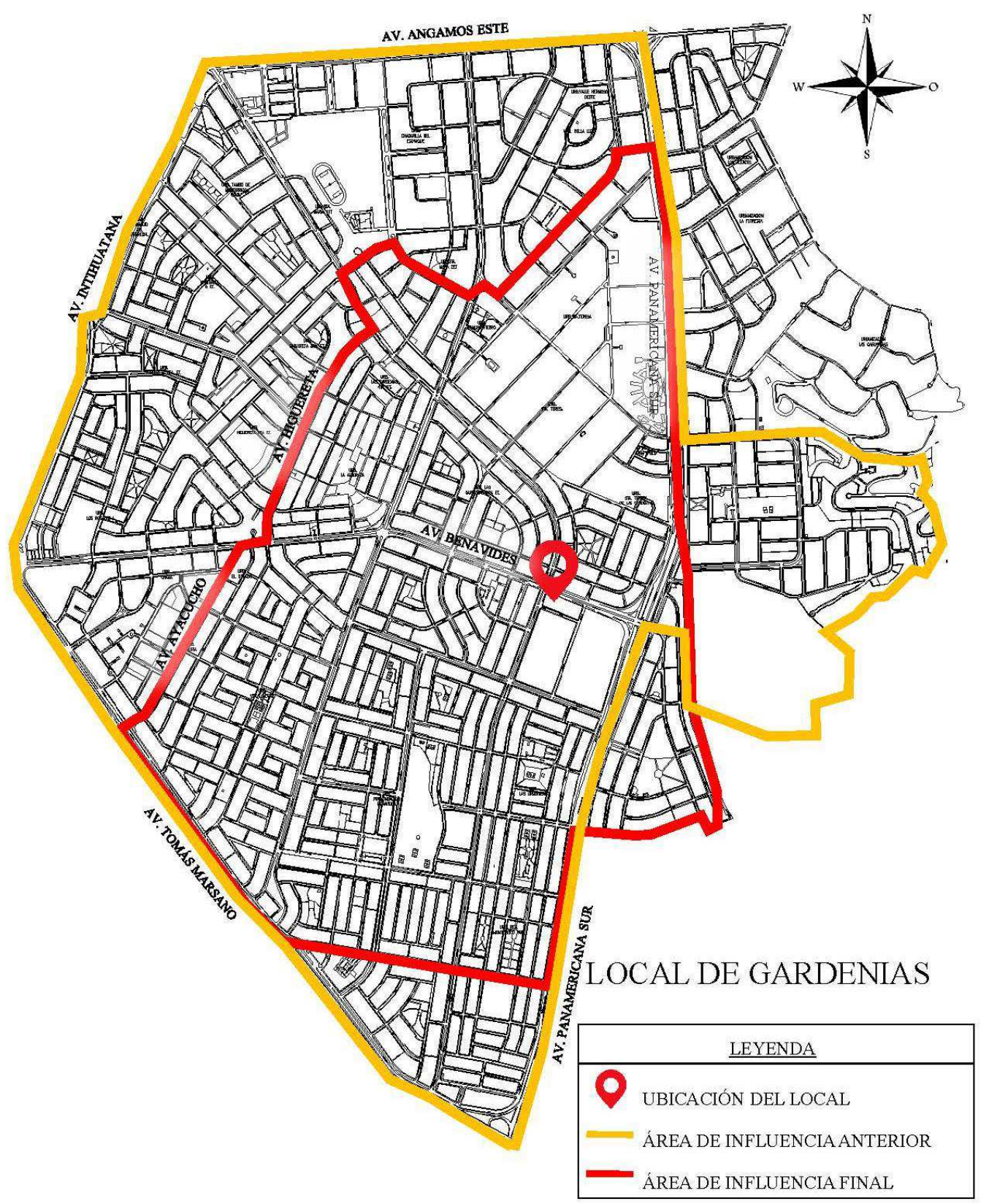




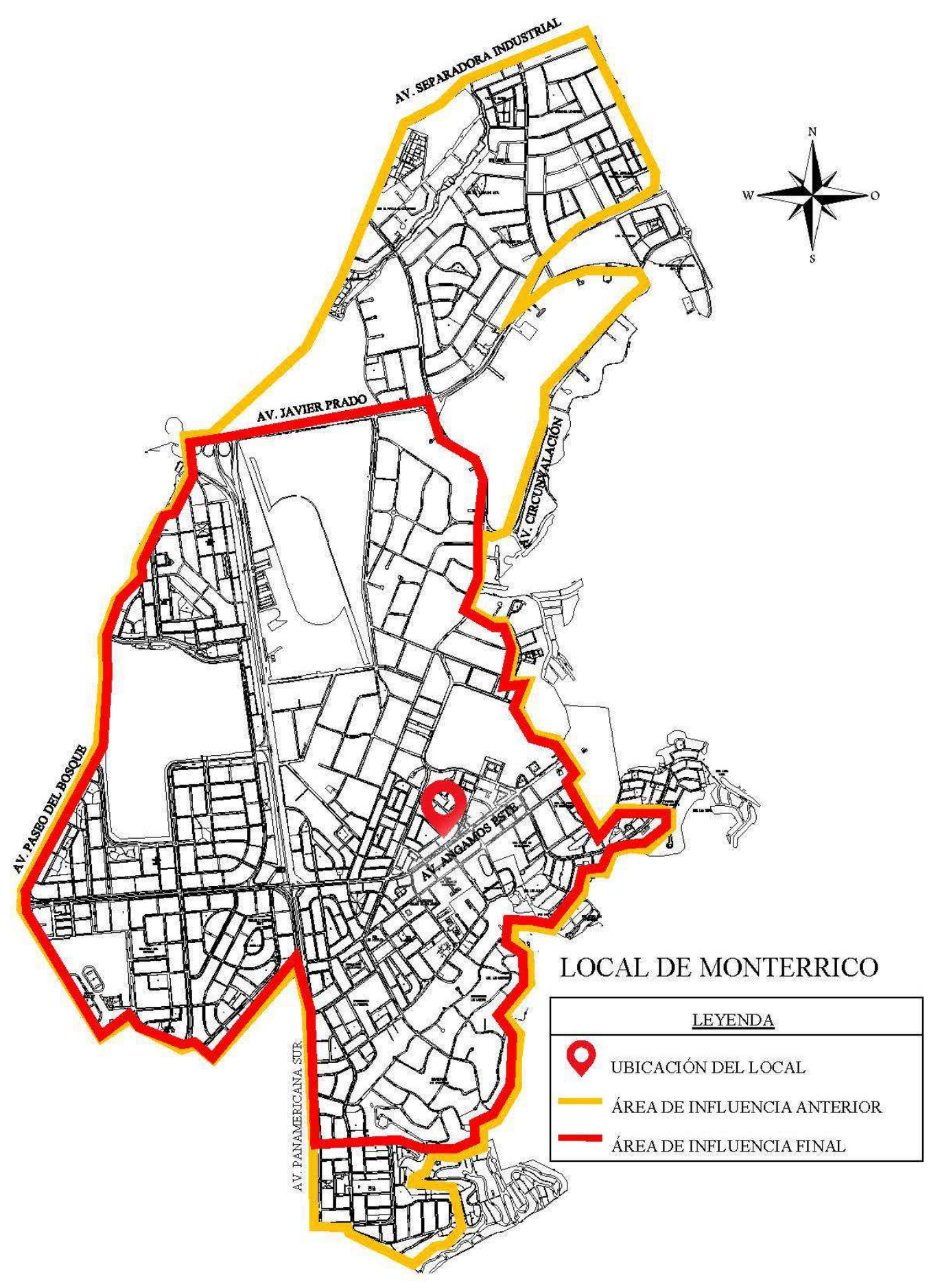




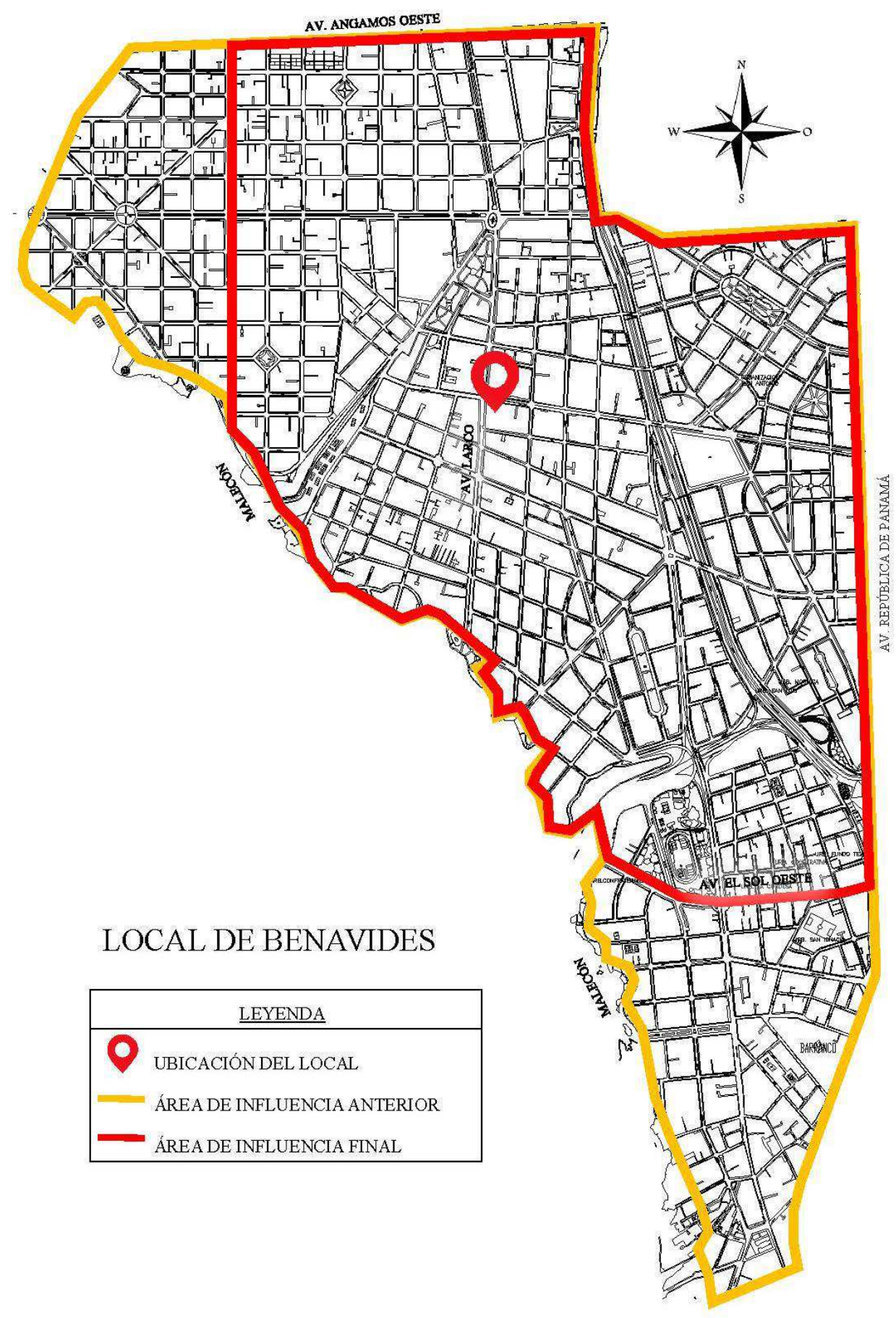




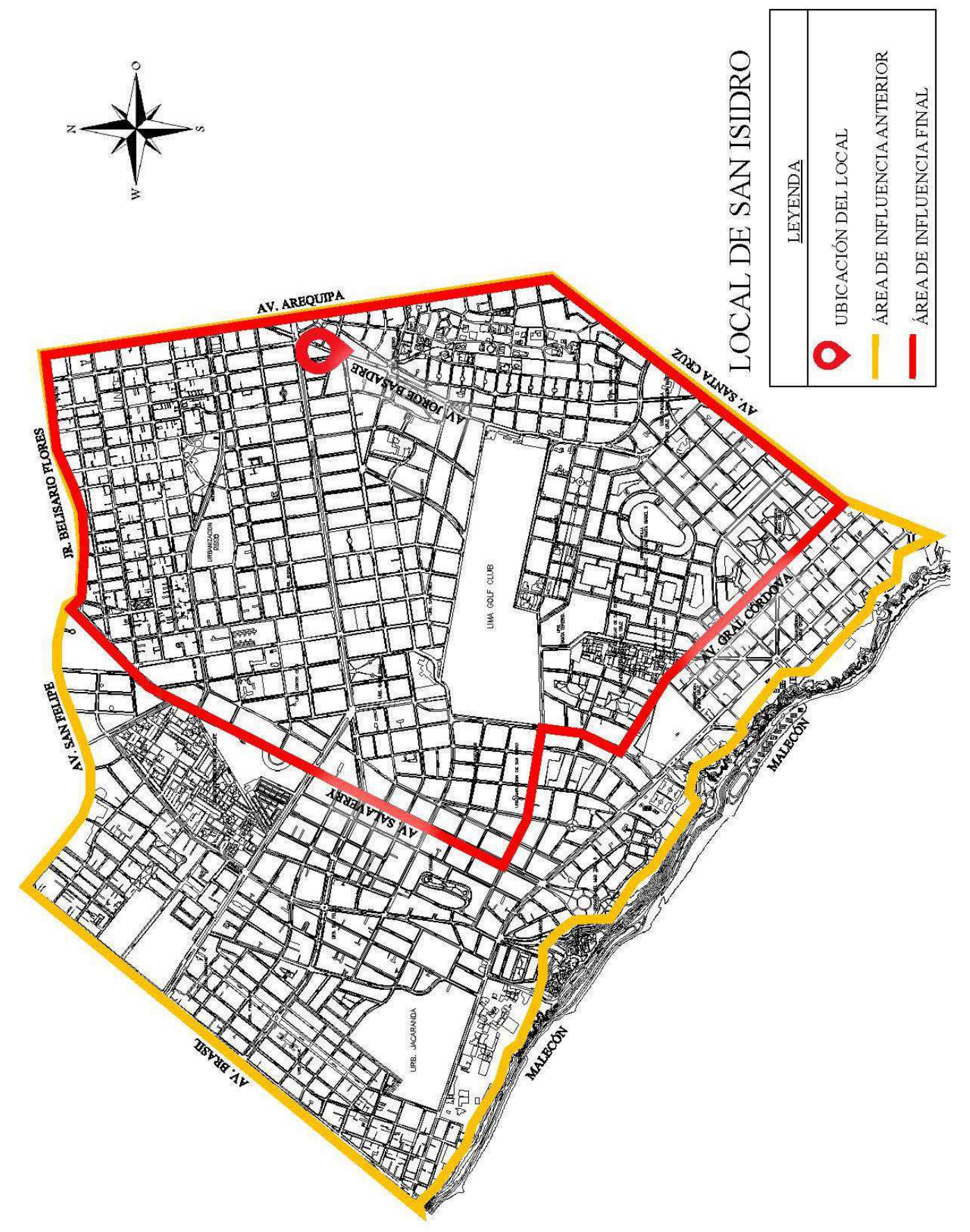




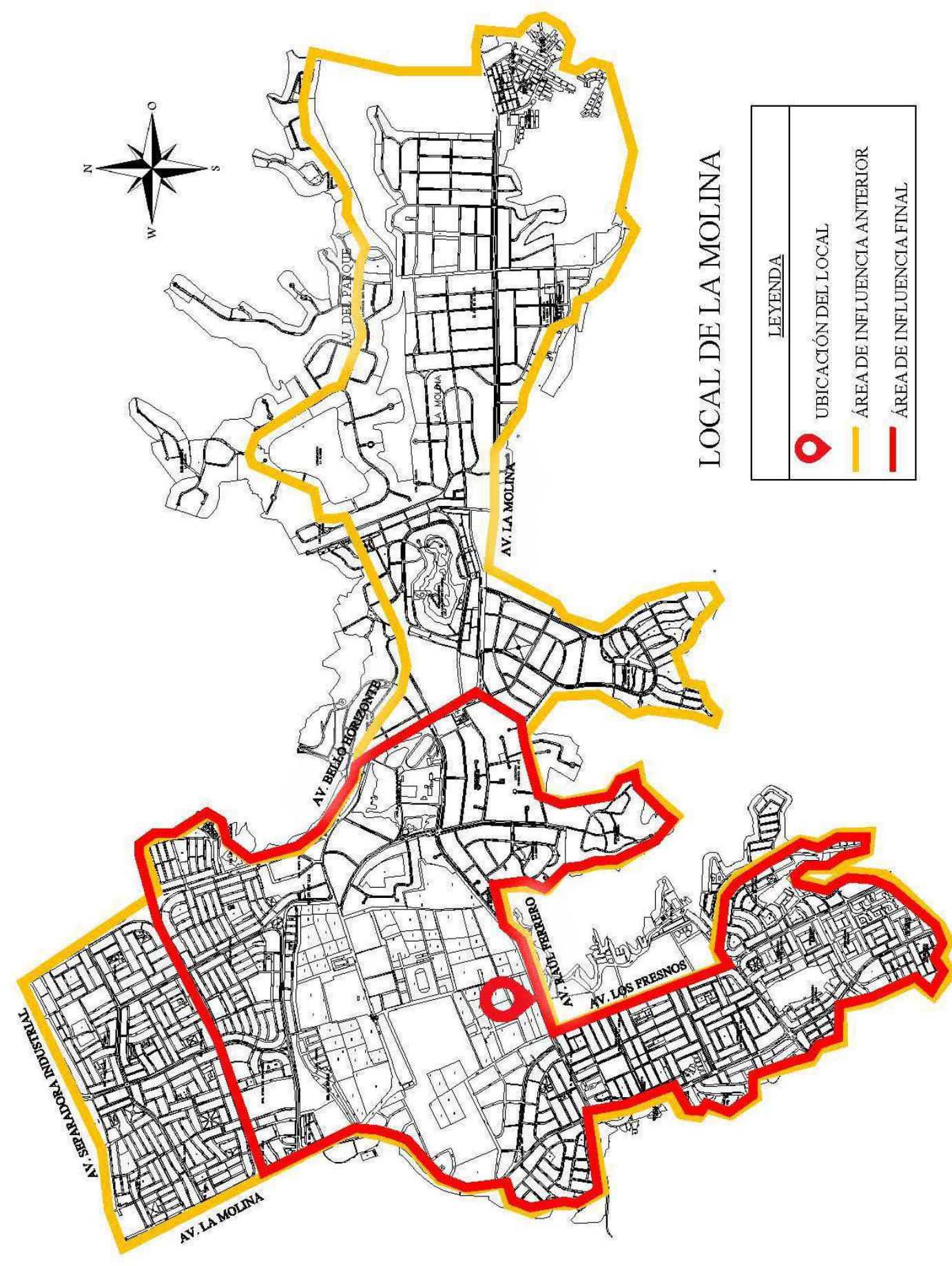


ANEXO 2

Empaque nuevo
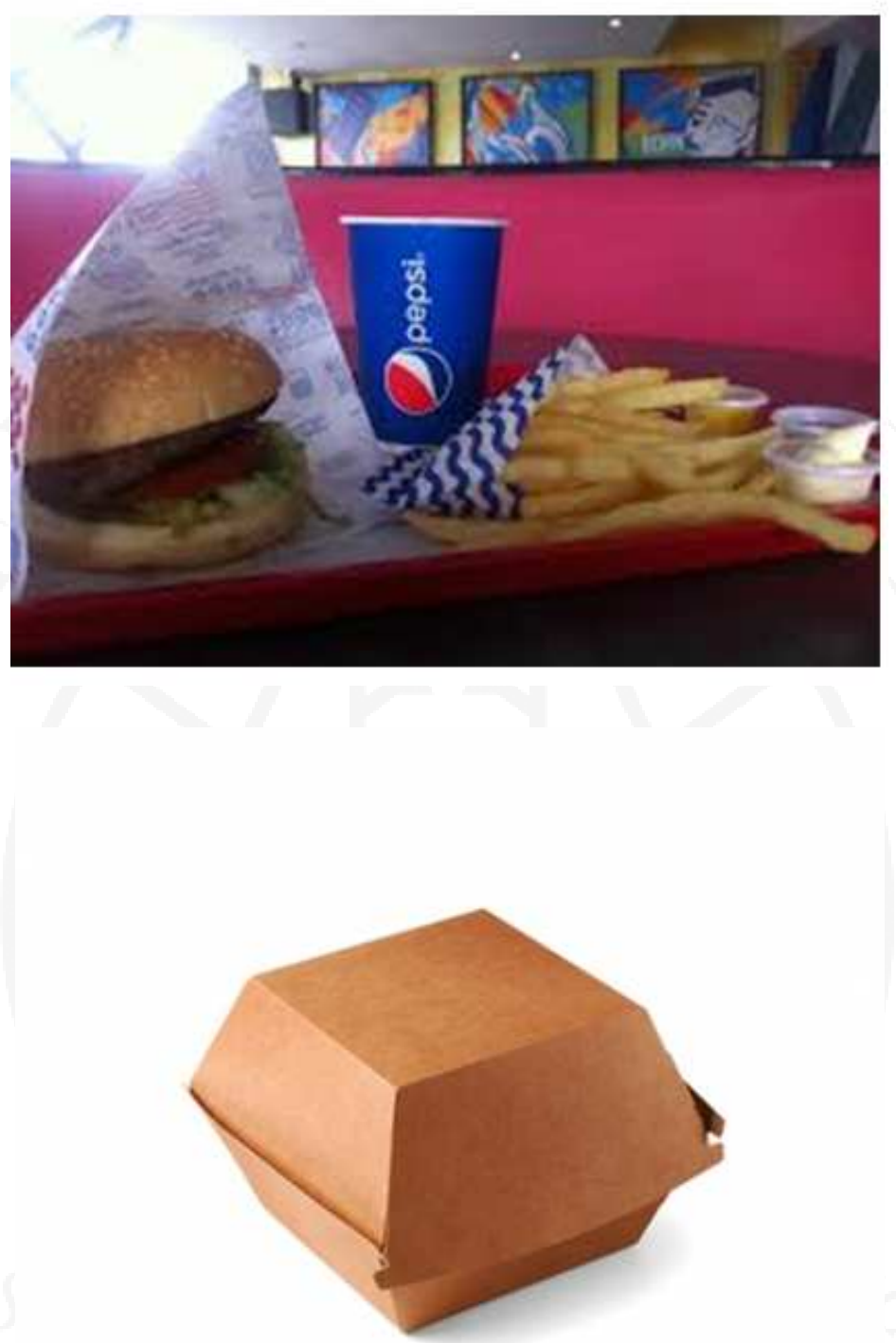